\title{
Cohesins and Cohesin-Regulators in Meiosis
}

\author{
Adela Calvente and José L. Barbero \\ Cell Proliferation and Development Department, Centro de Investigaciones Biológicas, \\ Spain
}

\section{Introduction}

Cells have rigorous mechanisms controlling sister chromatid cohesion during cell division to ensure proper distribution of genetic material to daughter cells. Errors in these mechanisms often lead to aneuploidy, frequently implicated in cell death, tumour development and infertility. The main actor in this process is a four-protein complex called the cohesin complex. The role of cohesin complex in chromosome segregation is mediated by the formation of a ring-like structure, which entrapped replicated DNA. The dynamic of the cohesin ring is regulated by a still undetermined number of cohesin-interacting proteins. These cohesin-regulators were essentially identified and studied in relation with the cohesion function of cohesin complexes. In the last years, we have improved our understanding of the key players in the regulation of sister chromatid cohesion during cell division in mitosis and meiosis. During meiosis the formation and disassemble of synaptonemal complex (SC), the recombination between homologue chromosomes and the maintenance of sister chromatid cohesion until metaphase II - anaphase II transition require unique features and players participating in the control of chromosome segregation. While in mammalian mitosis there are essentially two cohesin complexes, which only differ in the STAG subunit (STAG1 or STAG2), in meiosis several cohesin complexes composed by specific and unspecific meiotic cohesins coexist and probably they develop different functions depending of their spatio-temporal chromosome localization. On the other hand, a correct control of chromosome cohesion in meiosis involves specific regulators that monitor the sequential cohesin release during both meiotic divisions. Recently excellent papers have appeared in the literature looking in depth on the molecular control of sister chromatid cohesion and cohesins in cell division. In this chapter, we review the implication of cohesins and cohesin-interacting proteins in meiosis-specific processes and chromosome dynamic. Furthermore due to the increasing relevance of cohesins in human syndromes, we briefly point how problems in their tasks during mammalian mitotic and meiotic cycle drive to pathological situations.

\section{Cohesin basic concepts}

The pair of sister chromatids produced after DNA replication must be maintained together throughout the G2 phase and until its segregation to ensure a correct cell division. Thus, the sister chromatid cohesion is established during S phase (Miyazaki \& Orr-Weaver, 1994) and although in mitosis the cohesion is released during prophase and prometaphase in arms (Hauf et al., 2005), the sister chromatid are joined at centromeres until the onset of anaphase. In meiosis, there are two consecutive chromosome divisions, segregating homologous 
chromosomes in anaphase I and sister chromatids in anaphase II. Thus the cohesion regulation presents specific characteristics of this kind of cell division, and whereas the arm cohesion is lost at anaphase I, the centromere cohesion is released at anaphase II (Watanabe, 2004). Since both cohesion releases follow the same pathway in meiosis, the meiotic centromere cohesin complexes must be protected until the second meiotic division (Kitajima et al., 2004). At any case, mitosis and meiosis, the multi-protein complex responsible of sister chromatid cohesion is called cohesin complex and it was first characterized in Saccharomyces cerevisiae and Xenopus laevis (Losada et al., 1998, Michaelis et al., 1997). The cohesin complex is composed by four subunits: two structural maintenance of chromosomes family proteins (SMC1 and SMC3), one a-kleisin subunit (SCC1/RAD21), and a HEAT-repeat domain protein (SCC3/SA/STAG) (Nasmyth \& Haering, 2005). The most of components of the cohesin complex are conserved from yeast to humans (Uhlmann, 2001) but there are specific subunits depending on the species or the cell division type. The most conserved cohesins are the SMC proteins, which form a V-shaped heterodimer, representing the core of the cohesin complex (Haering et al., 2002). Higher eukaryotes have two mitotic SA/STAG family members, SA1/STAG1 and SA2/STAG2 (Carramolino et al., 1997), which do not coexist and are present in different cohesin complexes (Losada et al., 2000). In germ cells have been characterized distinct meiosis-specific subunits of cohesin complex in different organisms. In mammals, a meiotic paralogue of SMC1 has been described, the SMC1 $\beta$, thus the subunit presents in mitosis and meiosis is called SMC1a (Revenkova et al., 2001). In yeast and mammals REC8 is the meiotic paralogue of SCC1/RAD21 subunit (Eijpe et al., 2003, Molnar et al., 1995, Watanabe \& Nurse, 1999) and in mice a new a-kleisin has been identified recently, the RAD21L, a paralogue of RAD21 (Gutierrez-Caballero et al., 2011, Ishiguro et al., 2011, Lee \& Hirano, 2011). RAD21L interacts with STAG3 (meiosis-specific SCC3 subunit) and with the three described SMC cohesin subunits, SMC1a, SMC1 $\beta$ and SMC3. STAG3 is the meiosis-specific paralogue for STAG1/2 in mammals (Pezzi et al., 2000, Prieto et al., 2001). Whereas these cohesin subunits, RAD21L, REC8, STAG3 and SMC1 $\beta$, are meiosisspecific and they are present specifically in spermatocytes and oocytes (Garcia-Cruz et al., 2010, Herran et al., 2011, Prieto, et al., 2001), different cytological and molecular analysis show the participation of the SMC1a, RAD21 and STAG2 in mammalian mitosis and meiosis (Prieto et al., 2002, Revenkova et al., 2004, Revenkova \& Jessberger, 2006). Characterization of distinct meiotic cohesin complexes containing REC8, RAD21 or RAD21L as a-kleisin subunits, which have distinct localization patterns and dynamics, as well as the simultaneous presence of SMC1a and $\beta$-containing complexes and the presence of STAG2 and STAG3 in mammalian meiosis suggest a large variety of putative cohesin complexes formed by combinations of cohesin subunits (Suja \& Barbero, 2009). The most accepted model of the cohesin complex organization describes a heterodimer of SMC proteins jointed by their hinge domains. The ATPase heads of SMC1 and SMC3 are connected by the akleisin, forming a tripartite ring and finally the SCC3 subunit interacts with SCC1 via SCC1's C-terminus (Fig. 1A) (Haering, et al., 2002). Two major models, which are not mutually exclusive, have been proposed for the cohesin complex function in sister chromatid cohesion and its interaction with the DNA molecules. The first one is based on the electronic microscopy results and structural characteristics of SMCs and described a cohesin complex forming a ring-like structure (Fig. 1B), which mediates cohesion by embracing chromatin fibers of both sister chromatids (Gruber et al., 2003). The second model was named handcuff model, it involves the participation of two cohesin rings formed by SMC1/SMC3/SCC1 subunits which interacts in an SCC3-dependent manner (Fig. 1C). In this model each sister chromatid is encircled by a tripartite cohesin ring (Zhang et al., 2008a). 
The activity of the cohesin complex is closely related to the action of three cohesin cofactors: PDS5, WAPL (Fig. 1A) and Sororin. PDS5 is associated with cohesins but in a less tightly bound manner than the cohesin complex proteins. In vertebrates there are two PDS5 homologues, PDS5A and PDS5B. The role of PDS5 is related to the maintenance of cohesion and the modulation of the interaction of cohesin complex with the chromatin (Losada et al., 2005). WAPL is involved in heterochromatin organization in Drosophila melanogaster (Verni et al., 2000) and in human cells regulates the resolution of sister chromatid cohesion during prophase (Gandhi et al., 2006).
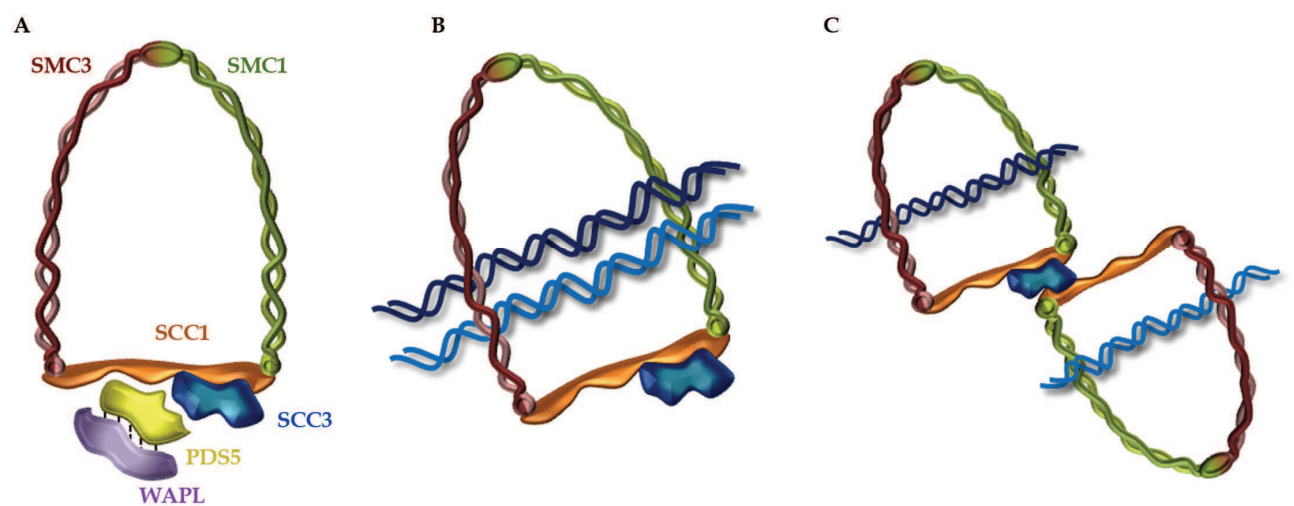

Fig. 1. Cohesin complex organization and cohesion models.

A. The cohesin complex is formed by four proteins: SMC1, SMC3, SCC1 and SCC3 (green, red, orange and blue piece respectively). The SMC1, SMC3 and SCC1 subunits form a ringlike structure. The SCC3 protein interacts with SCC1 to complete the cohesin complex. The cofactors PDS5 (yellow piece) and WAPL (purple piece) interact to form a protein complex, which is associated to the cohesin complex by SCC3 interaction. B. Ring-embraced model of cohesion. A single cohesin complex hugs the two sister chromatids. C. Handcuff model of cohesion. Two cohesin rings interacts by a single SCC3 molecule. Each cohesin ring encircles a single chromatid.

Regarding to the Sororin, it has been described in culture cells that this protein have a role in centromere cohesion, probably it is implicated in the protection of centromeric cohesin complexes (Diaz-Martinez et al., 2007). Moreover Sororin seems to have a role in the cohesion establishment during replication (Lafont et al., 2010). The implication of all these cofactors in meiosis is a wide field of study nowadays. The importance of cohesins, cohesin complex and cohesion cofactors not only consists in keeping jointed both sister chromatid and then ensure the bipolar attachment and the chromosomal segregation (Tanaka et al., 2000) in mitosis and meiosis, but the cohesins acquire a pivotal role in many different aspects of meiosis and chromosome dynamics such as the modulation of gene expression, the double strand breaks (DSBs) repair, axial elements (AEs) formation or pairing and synapsis of homologous chromosomes. In this chapter some of those different roles of cohesins and cohesion cofactors are reviewed, giving special attention to the specificity of some cohesin subunits to specific functions. 


\section{Loading, establishment, maintenance and release of cohesin complexes}

Chromosome segregation control is managed by an intricate network of events, which assures that each daughter cell receives the right chromosome number, equal amount of chromosomes in mitosis and a haploid recombined chromosomal pack in meiosis. On one hand, fails in mitotic chromosome segregation compromises the viability of the organism, on the other hand fails in meiotic chromosome segregation jeopardizes the fertility of individuals. The importance of cohesion must be taken into account from the loading of cohesins to the establishment of cohesion, maintenance of cohesive function and finally the removal of cohesin complexes. In this context, the association/dissociation of sister chromatids is a wellcontrolled process that involves the role of different cohesin-interacting proteins. The loading of cohesin complexes to chromosomes occur near the G1 to S phase previous to cell division, thus it would be easy to think that the regulators of cohesin loading would be similar in mitosis and meiosis. In fact, most of them have been first described in yeast mitosis and afterwards a similar meiotic function was identified in some cases. Although we do not should forget that the transition from mitosis to meiosis could be trigger from the premeiotic $S$ phase, and taking into account the presence of meiotic cohesin complexes and the special regulation of meiotic cohesion release, crucial differences might exist between mitosis and meiosis. It was described in S. cerevisiae that the loading of cohesin complexes depends on the SCC2/SCC4 adherin complex (Ciosk et al., 2000). This loading is not sufficient for the cohesion function in chromosome segregation and the Eco1/Ctf7p acetyltransferase is required for the establishment of cohesion in mitotic yeast chromosomes (Skibbens et al., 1999, Toth et al., 1999). In humans, two Eco1 orthologues have been identified: ESCO1 and ESCO2. Both proteins exhibit not redundant acetyltransferase activity and the depletion of any of them by siRNA cause defects in sister chromatid cohesion and chromosome segregation. However, in S-phase the role of both proteins seems to be directly related to the cohesion establishment and do not with the cohesin loading (Hou \& Zou, 2005). The substrate of Eco1/ESCO1 is SMC3 in both human and yeast cells, being required the acetylation of SMC3 for sister chromatid cohesion. The acetylation of SMC3 could regulate its interaction with SCC1, promoting the turn from a chromosome-bound cohesin complex into a cohesive complex (Zhang et al., $2008 \mathrm{~b}$ ), suggesting that the cohesin complexes with acetylated SMC3 may be stably bound to chromosomes (Unal et al., 2008). The activity of Eco1 could be facilitated due to its interaction with PCNA (proliferating cell nuclear antigen) (Moldovan et al., 2006). The acetylation of SMC3 is maintained until metaphase - anaphase transition and its deacetylation in yeast mitosis depends on Hos1, but this deacetylase cannot act until the SCC1 cohesin subunit is cleaved by a protease called Separase, recycling then the tripartite open ring of cohesin (Beckouet et al., 2010, Borges et al., 2010). In mammalian mitosis the deacetylase responsible for SMC3 deacetylation has not been identified, moreover the cycle of SMC3 acetylation/deacetylation in meiosis is still poorly known.

The release of cohesion in mitotic prophase and anaphase follows different pathways of resolution (Waizenegger et al., 2000). In mitosis, the arm cohesion is released during prophase in a Separase-independent manner, it depends on the phosphorylation of SCC3/SA2/STAG2 subunit by Aurora B and Polo-like kinases (Hauf, et al., 2005), but the correct chromosome segregation depends on the centromeric cohesion, which is maintained until anaphase onset and then released by the Separase activity. The release of cohesin complexes from centromeric chromatin at mitotic metaphase - anaphase transition is mediated by the Separase, a specific protease that cleaves the SCC1 subunit of the cohesin complex (Uhlmann et al., 1999), destabilizing the association of cohesins to 
chromatin. Before anaphase, Separase remains inactivated by binding to its specific inhibitor Securin (Ciosk et al., 1998). Activation of the anaphase promoting complex/cyclosome (APC/C) leads to ubiquitination of Securin, allowing cleavage of SCC1/RAD21 by Separase and triggering the onset of anaphase (Uhlmann et al., 2000). In meiosis there are two consecutive chromosome segregations which are triggered by a Separase-dependent mechanism of lost of cohesion. During first meiotic division, the cohesin complexes at chromosome arms are removed during the metaphase I - anaphase I transition, allowing segregation of recombined homologues to opposite poles. In the second meiotic division, the cohesion is released from centromeres and sister chromatids are segregated to opposites poles to generate haploid gametes. Then, this type of cell division presents unique characteristics in sister chromatid cohesion removal and centromere cohesion protection. This is necessary to prevent premature separation of sister chromatids in order to avoid aneuploidy in the resulting gametes. Related to the centromere protection a protein family was indentified in fission yeast, the Shugoshins: Sgo1 and Sgo2 (Kitajima, et al., 2004). In these organisms Sgo1 seems to be essential in meiosis and Sgo2 is mostly implicated in mitotic division. The activity of Sgo1 and Sgo2 is related to the recruitment of a serine/threonine protein phosphatase 2A (PP2A) (Kitajima et al., 2006). In humans these proteins are called SGOL1 and SGOL2 and in mitosis they also collaborate with PP2A. In mice it has been described the localization of SGOL2 in male meiosis and it corresponds with a protection function of centromeric cohesion during first meiotic division (Gomez et al., 2007). An interesting model is the SGOL2deficient mouse, where a precocious dissociation of the meiosis-specific REC8 cohesin complexes from anaphase I centromeres was observed (Llano et al., 2008), demonstrating the specific implication of SGOL2 in centromere protection during meiosis.

The cohesin-regulators PDS5 and WAPL are also involved in the opening/closing of cohesin ring by interactions with different cohesin subunits. These cofactors are not required for cohesin association to chromosomes but they are necessary for cohesin complex dynamics. The action of PDS5 is related to its interaction with the SA1 and SA-containing complexes in somatic cells (Sumara et al., 2000). In vertebrates two PDS5 proteins have been characterized: PDS5A and PDS5B. Both are large HEAT-repeat proteins that bind to chromatin in a cohesin-dependent manner in human cells and Xenopus egg extracts. RNAi depletion of PDS5A and PDS5B show that both are needed for maintaining cohesion, altering preferentially centromeric cohesion in Xenopus egg extracts. (Losada, et al., 2005). Mice lacking PDS5B function die shortly after birth and exhibit multiple developmental anomalies that resemble those found in humans with Cornelia de Lange syndrome (CdLS), indicating a relevant function for PDS5B beyond chromosome segregation, but there are no discernible defects in sister chromatid cohesion (Zhang et al., 2007). Despite of these contradictory results, the function of PDS5 has been related with the maintenance of sister chromatid cohesion during G2 (Panizza et al., 2000). Although, whether PDS5 also has a function in sister chromatid resolution remains to be determined. Another interesting cohesin cofactor is the product of the previously identified Drosophila wings apart-like (Wapl) gene, involved in heterochromatin organization (Verni, et al., 2000). Human WAPL regulates the resolution of sister chromatid cohesion and promotes cohesin complex removal by direct interaction with the RAD21 and SA/STAG cohesin subunits (Gandhi, et al., 2006). Thus, WAPL seems to destabilize cohesins. It has been proposed that PDS5 and WAPL form a protein complex, which in association with SCC3 cohesin subunit antagonizes the establishment of cohesion, calling the WAPL-PDS5 anti-establishment complex. 
Skibbens proposed a model of cohesion establishment where the recruitment of PDS5WAPL complex onto SCC3 subunit prevents the binding of cohesin complexes by destabilizing cohesin-cohesin association. During S phase, Eco1/ESCO1 acetylates SMC3, which inhibits the WAPL-PDS5 activity temporally (Skibbens, 2009). After S phase, PDS5 would stabilize the cohesin complexes activity.

Sororin has been implicated in centromere cohesion. This protein was firstly identified in a screen for substrates of the APC in vertebrates and no homologues have been described in other organisms. Different results in somatic cells suggested that Sororin interacts with the cohesin complex and it is essential for the maintenance of sister chromatid cohesion. Sororin is ubiquitinized and degraded after sister chromatid cohesion is dissolved (Rankin, 2005). Studies on Sororin-depleted and Shugoshin-depleted cells indicate that both proteins might act in concert in the protection of centromeric cohesion (Diaz-Martinez, et al., 2007). Sororin is also needed for maintaining stable chromatin-bound cohesin and DSBs repair in G2 (Schmitz et al., 2007). The Sororin recruitment depends on Eco2/ESCO2, both are subtrates of APC and its activity is related to the DNA replication (Lafont, et al., 2010). In agreement with these findings, Nishiyama reported that DNA replication and cohesin acetylation promote binding of Sororin to cohesin complex and that Sororin displaces WAPL from its binding partner PDS5, thus it would contribute to maintenance of a stable binding of cohesin to chromatin (Nishiyama et al., 2010).

Despite of the relevant roles in chromosome cohesion control suggested by all these results, there are few data regarding to the putative functions of cohesion cofactors such as SCC2/SCC4, Eco1/ESCO1, Eco2/ESCO2, WAPL, PDS5 or Sororin in chromosome segregation in meiosis.

\section{Roles of the cohesin-regulators in meiosis}

Updates there are no many evidences regarding to the specific implication of all the cohesion cofactors in meiosis. It is predictable that all of them might act in meiosis in a similar way to that described in mitotic cells or perhaps they acquire specific roles due to the particular regulation of meiotic division. Update the unique indication that ESCO2 have a role in meiosis was the identification of $E s c o 2$ gene as a candidate to be a potential regulator of the transition from mitosis to meiosis in mammals, identifying by means microarray database in both testis and ovary of mouse (Hogarth et al., 2011). The data are supported not only by a pattern of mRNA expression but also by protein immunolocalization, showing on one hand that Esco2 is expressed in testis and ovary, specifically in the embryonic gonad, and on the other hand that ESCO2 localized to the nucleus of spermatocytes at early prophase I. This last probe was performed by immunofluorescence techniques over testis sections at different ages. At 10dpp (days post-partum) male mice, ESCO2 was presented at preleptotene and leptotene diffusely and from 15dpp this protein is located at pachytene in a discrete domain within the nuclei. Our laboratory is actually studying the ESCO2 implications in meiosis and using the same antibody (Bethyl Laboratories, A301-689A) we have identified that the discrete domain observed by Hogarth et al., is in fact the XY body (Figs. 2 and 3). We have analyzed the male mice meiosis over squashes of seminiferous tubules (Page et al., 1998, Parra et al., 2004) and spreads of meiocytes (Peters et al., 1997, Viera et al., 2009a) and performed the doubleimmunolocation of ESCO2 and SYCP3 (Santa Cruz Biotechnology, sc-74569). Our results indicate that the ESCO2 acetyltranferase is present over the chromatin of XY body from 
zygotene to late stages of prophase I, detecting a more intense signal at pachytene (Fig. 2 and 3 A). We distinguish the $X Y$ body in squashed spermatocytes because of it usually is located at nuclear periphery and its AEs are partially unsynapsed due to this pair of chromosomes share only a homologue region called pseudoatosomal region, which the SC is exclusively formed in. Also the DAPI chromatin staining led us to identify the XY body undoubtedly in squashes (Fig. 2D). At pachytene nucleus the synapsis between autosomes is completed, which can be detected by SYCP3 immunolabeling (Fig. 2 and 3 B).

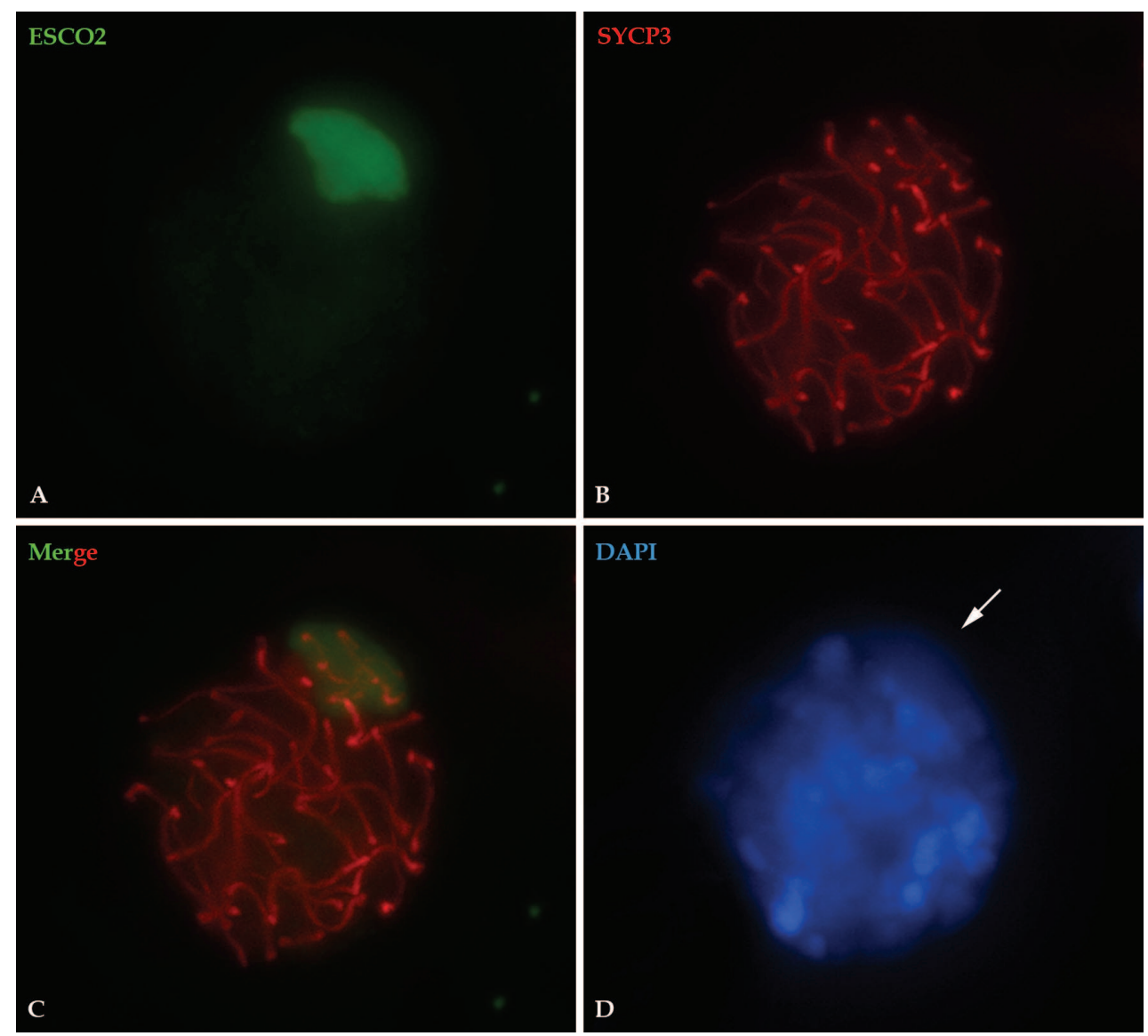

Fig. 2. Immunolabeling of ESCO2 (green) and SYCP3 (red) at pachytene after squasing of spermatocytes.

A. ESCO2 immunolabeling (rabbit anti-ESCO2 Bethyl Laboratories, A301-689A; 1:50 dilution) mark the $X Y$ body at pachytene. FITC-conjugated anti-rabbit IgG secondary antibody (Jackson Laboratories) was used at 1:150 dilution. B. SYCP3 (mouse monoclonal antibody anti-SYCP3. Santa Cruz Biotechnology, SCP-3 (D-1): sc-74569; 1:100 dilution) mark the LEs of synapsed autosomes and the AE/LEs of the XY body. DyLight594-conjugated anti-mouse IgG secondary antibody (Jackson Laboratories) was used at 1:150 dilution. C. The merge image of ESCO2 and SYCP3 signals is shown. D. The chromatin was 
counterstaining with DAPI in blue (4',6-diamidino-2-phenylindole, SIGMA). The XY body is indicated (white arrow). After mounting the preparations with Vectashield (Vector Laboratories), the meiocytes were visualized using a Leica AFX6000LX multidimensional microscopy. The images were captured with LAS_AF software and analyzed and processed with public domain ImageJ and Adobe Photoshop CS3 softwares. All images are the result of superimposition of all the focal planes occupying the total volume of a pachytene mouse spermatocyte after squashing of seminiferous tubules.

We have not detected any ESCO2 labelling over the autosomas at any stage of meiosis. Since the $\mathrm{X}$ and $\mathrm{Y}$ chromosomes in all eutherian mammals preserve only a small region of homology, the genetic and morphological differentiation of sex chromosomes mark the XY behaviour during meiosis, which cannot be comparable with autosomes. Thus, structural modifications in the unsynapsed AEs of $X Y$ pair have been identified. Moreover, modifications in the distribution of different cohesin subunits have been also observed, as the preferential location of REC8 in the synapsed region of the XY body at pachytene (Page et al., 2006). However, our results show that the ESCO2 labelling embrace all the chromatin of sex chromosomes, similar signals have been detected after immunostaining of $\gamma-\mathrm{H} 2 \mathrm{AX}$ and surprisingly the cohesin subunit RAD21L has been also observed in the XY chromatin at pachytene and diplotene (Herran, et al., 2011, Ishiguro, et al., 2011).

The presence of RAD21L over the XY chromatin has been explained as part of the sexual dimorphism observed regarding to the detection of RAD21L in mice and the authors pointed to a specific role of this meiotic cohesin subunit in the pairing and development of the sex body (Herran, et al., 2011), although deep studies should be performed to understand the role of a cohesin subunit in all sex chromatin. $\gamma-\mathrm{H} 2 \mathrm{AX}$ is the histone variant derived from the phosphorylation of H2AX at serine 139 as consequence of DSBs (Mahadevaiah et al., 2001), however the presence of this chromatin modification in XY pair has been related to the transcriptional repression associated with the sex body (FernandezCapetillo et al., 2003).
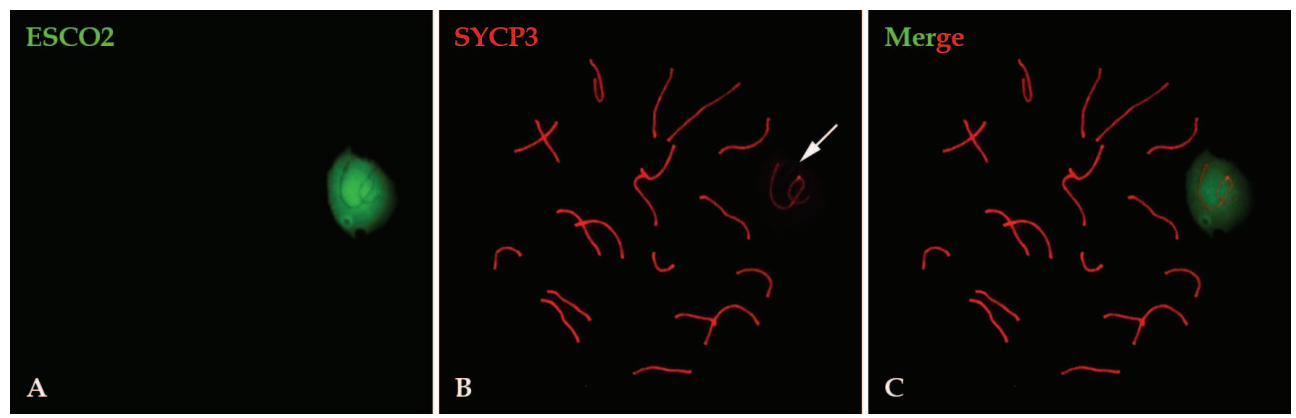

Fig. 3. Immunolabeling of ESCO2 (green) and SYCP3 (red) at pachytene after spreading of spermatocytes.

A. The immunolabeling of ESCO2 (rabbit anti-ESCO2 Bethyl Laboratories, A301-689A; 1:50 dilution ) mark the $X Y$ body at pachytene. FITC-conjugated anti-rabbit IgG secondary antibody (Jackson Laboratories) was used at 1:150 dilution. B. The LEs of synpased autosomes and the AE/LEs of the sex chromosomes (white arrow) are detected with an antiSCYP3 antibody (mouse monoclonal antibody anti-SYCP3. Santa Cruz Biotechnology, SCP-3 
(D-1): sc-74569; 1:100 dilution). DyLight594-conjugated anti-mouse IgG secondary antibody (Jackson Laboratories) was used at 1:150 dilution. C. Merge image of ESCO2 and SYCP3 signals. After mounting the preparations with Vectashield (Vector Laboratories), the meiocytes were visualized using a Leica AFX6000LX multidimensional microscopy. The images were captured with LAS_AF software and analyzed and processed with public domain ImageJ and Adobe Photoshop CS3 softwares.

During male meiosis, $\mathrm{X}$ and $\mathrm{Y}$ chromosomes are silenced in a process called Meiotic Sex Chromosome Inactivation (MSCI), it has been described that this chromosome inactivation is essential for male meiosis progression, thus the disruption of MSCI arrest the male meiosis at pachytene, being essential for male fertility (Fernandez-Capetillo, et al., 2003, Royo et al., 2010). According to the formation of $\mathrm{XY}$ body and its transcriptionally silenced status during spermatogenesis different histone modifications have been described at pachytene such as $\mathrm{H} 3$ and H4 deacetylation or H3-K9 dymethylation (Khalil et al., 2004). The specific function of ESCO2 in the sex chromatin of male mice is not known. However it has been described that this acetyltransferase could play a role in regulating transcription, specifically it has been suggested a transcriptional repression activity through the interaction of ESCO2 with chromatin modifying enzymes and with the CoREST complex, achieving the repression by means of histone modification (Kim et al., 2008). Moreover, the authors talk about an ESCO2containing complex, which has histone methyltransferase activity in culture cells. These evidences could link the presence of ESCO2 in sex chromatin and the MSCI process. Another cytological example of the specific presence of a cohesion cofactor in meiosis is related to WAPL localization. WAPL was found on axial and lateral elements of chromosomes (AE/LEs) in some prophase I stages in mouse spermatocytes (Kuroda et al., 2005) and oocytes (Zhang et al., 2008c) colocalizing with SYCP3, a constitutive protein of the SC; however, no more extensive study has been carried out on the role of WAPL in meiosis. It has been established that WAPL and PDS5 act as a protein complex during cohesion establishment and maintenance (see Skibbens, 2009 for further details); but there is no data about the possible presence of PDS5 in mammalian prophase I. However in budding yeast meiosis has been described that Pds5 is required for pairing of homologous chromosomes and this cofactor could have a role inhibiting the synapsis between sister chromatids. Depletion of Pds5 gives raise to fails in synapsis, hypercondense chromosomes and blocking meiocytes at pachytenelike stage (Jin et al., 2009). This result was preceded by the Pds5 fission yeast mutant that showed absence of SC formation (Ding et al., 2006). The action of Pds5 in pairing and synapsis could be related with the interaction between both proteins and the Pds5 capacity of modulating Rec8 activity in both fission and budding yeast (Ding, et al., 2006, Jin, et al., 2009). Although these studies point out to the importance of the structural organization of meiotic chromosomes and the implication of cohesin complexes and cohesion cofactor in such important process as synapsis of homologous chromosomes, further cytological and biochemical studies are needed to characterize the role of PDS5 and WAPL during meiosis. Are those cohesion cofactors acting in unknown manner or their activity is related to the cohesion modulation? This is an unresolved question yet. Finally a recent molecular-genetic approach have shown that the cohesin-loading factor Scc2 and the subunits Scc3 and Smc1 of the cohesin complex are required for activating the production of the meiosis-specific subunit Rec8 in the S. cerevisiae (Lin et al., 2011). This result suggests that Scc2 could play a dual role in gene regulation and sister-chromatid cohesion during meiotic differentiation. Although the mechanism is poorly understood yet, the role of cohesins and cohesion cofactors in gene regulation has been largely studied in the somatic line (Chien et al., 2011, Dorsett, 2011, 
Newman \& Young, 2010, Ong \& Corces, 2011). However, meiosis-specific gene regulation is a future field of study where probably different groups are work in.

\section{To form bivalents: Cohesion, synapsis and recombination}

Two of the most important phenomena that characterize the meiosis are the SC formation and the reciprocal homologous recombination. Both are meiosis-specific and are implicated in the physical connexion of homologous chromosomes to form and maintain the bivalents. In this context, the cohesion is the third pivotal factor. Since the cohesion stabilizes the joint between sister chromatids from $S$ phase until their segregation, it is easy to think that the cohesin complexes are needed to ensure that both sister chromatids of each homologous chromosome act in a single manner during prophase I, in a cellular context where the AEs formation, the synapsis and the meiotic recombination between homologous chromosomes is taking place. This would be the role of cohesin complexes in sister chromatid cohesion, its canonical function. Thus, during first meiotic division these three events: cohesion, synapsis and recombination, must be perfectly coordinated. However, the existence of meioticspecific cohesins and its specific localization during first meiotic division become evident that the meiotic cohesin complexes could be implicated in SC formation and recombination directly further than the canonical function of chromatid cohesion.

\subsection{The importance of individual cohesin subunits to synapsis}

The SC is a meiosis-specific proteinaceous structure formed by two lateral elements (LEs), derivate from AEs of chromosomes, and a central element (CE) connected by transverse filaments (TFs). It is known that this meiotic structure play important roles in the condensation and pairing of chromosomes and also has a close relationship to the programmed DSBs formation and resolution (Page \& Hawley, 2004). The formation of SC between homologous chromosomes is highly conserved in evolution, it derivates in the synapsis of homologous chromosome during the meiotic prophase I. One of the first references of the close relationship between the SC and cohesion was observed in budding yeast (Klein et al., 1999). In these organisms the cohesin subunit Smc3p presents a continuous localization along chromosome cores similar to that described for SC proteins in rat (Schalk et al., 1998). Klein et al., included a functional analysis, they studied the Smc3 and Rec8 mutants and observed that both were defective in cohesion, formation of AEs and SC assembly, demonstrating in yeast that the cohesins were essential not only for the meiotic sister chromatid cohesion but also for the synapsis. Moreover they postulated that the meiotic cohesin complexes were in fact part of AEs of chromosomes. However, two years later Pelttari et al., went farther and proposed that the cohesin axis was preformed along each chromosome and might act as the organizing framework for AE/LEs formation. This proposal was based on the evidences that Sycp $3^{--}$mice were able to form a cohesin axis even in the absence of AEs (Pelttari et al., 2001). Contrary, the Rec $8^{-\%}$ and $\operatorname{Smc} 1 \beta^{-\%}$ mice showed AEs partially assembled (Revenkova, et al., 2004, Xu et al., 2005). In rat spermatocytes the interaction between SMC cohesin subunits and SYCP2 and SYCP3, the main components of AEs and LEs, was also studied, concluding that the cohesin axes were essential in the SC formation and synapsis progression during early stages of prophase I (Eijpe et al., 2000, Eijpe, et al., 2003). These first observations pointed to the contribution of cohesins not only to form the AEs but also as part of AEs/LEs and then to its function in synapsis. Since then 
we have known different examples which closely relate the SC proteins and the synapsis progression to cohesin localization and function in meiosis. In the table 1 we summarize some of examples of the contribution of cohesin to SC formation and synapsis that we detail forward.

\begin{tabular}{|c|c|c|c|}
\hline Organism & Cohesin & $\begin{array}{l}\text { Role in AE/LEs formation or } \\
\text { synapsis }\end{array}$ & Reference \\
\hline C. elegans & REC-8 & $\begin{array}{l}\text { Chromosome pairing } \\
\text { AE component } \\
\text { SC assembly }\end{array}$ & $\begin{array}{c}\text { Chan } 2003 \\
\text { Colaiacovo } 2006 \\
\text { Pasierbek } 2001\end{array}$ \\
\hline S. cerevisiae & $\begin{array}{l}\text { SMC3p } \\
\text { REC } 8\end{array}$ & $\begin{array}{l}\text { AE/LEs localization } \\
\text { SC assembly }\end{array}$ & Klein 1999 \\
\hline \multirow{3}{*}{ Rat } & $\begin{array}{l}\text { SMC1a } / \beta \\
\text { SMC3 }\end{array}$ & $\begin{array}{c}\mathrm{AE} / \mathrm{LEs} \text { formation } \\
\text { Interaction with SYCP2 and SYCP3 }\end{array}$ & $\begin{array}{c}\text { Eijpe } 2000 \\
\text { Revenkova } 2001\end{array}$ \\
\hline & REC8 & AEs assembly & \multirow[b]{2}{*}{ Eijpe 2003} \\
\hline & $\begin{array}{l}\text { SMC1a } \\
\text { SMC3 }\end{array}$ & Part of AEs & \\
\hline Tomato & $\begin{array}{l}\text { SMC3 } \\
\text { SMC1 } \\
\text { SCC3 } \\
\text { REC8 }\end{array}$ & $\begin{array}{l}\text { AE/LEs localization } \\
\text { Sequential assembly }\end{array}$ & $\begin{array}{l}\text { Qiao } 2011 \\
\text { Stack } 2009\end{array}$ \\
\hline \multirow[b]{2}{*}{ Grasshoppers } & SMC3 & AE/LEs localization & \multirow[b]{2}{*}{ Valdeolmillos 2007} \\
\hline & $\begin{array}{c}\text { SA1 } \\
\text { RAD21 }\end{array}$ & $\begin{array}{l}\text { Present in synapsed regions } \\
\text { exclusively }\end{array}$ & \\
\hline \multirow{5}{*}{ Mice } & STAG3 & Association to SC & Prieto 2001 \\
\hline & REC8 & Homologous SC assembly & Xu 2005 \\
\hline & RAD21L & AEs formation and synapsis & Herrán 2011 \\
\hline & SMC1a & Synapsis & James 2002 \\
\hline & SMC1 $\beta$ & AEs formation and SC assembly & Revenkova 2004 \\
\hline
\end{tabular}

Table 1. Role of different cohesin subunits in AE/LEs formation and synapsis

The evidences of the implications of cohesin complexes in SC assembly, pairing and/or AEs formation came from many different organisms and scientific approaches. In plants, a specific and intermittently localization of SMC3 in the AE/LEs has been observed in tomato by means immunogold labeling and electron microscopy in zygotene microsporocytes (Qiao et al., 2011, Stack \& Anderson, 2009), similar to that observed by light microscopy after the immunolabeling of SMC1, SMC3, SCC3 and REC8, although no all subunits presented the same pattern of accumulation and appearance during prophase I (Qiao, et al., 2011). In this vegetal species REC8, SMC1 and SMC3 are localized as foci from preleptotene which are arranged to AEs at leptotene but do not colocalize. However they exhibit colocalization in synapsed regions at zygotene and pachytene. SCC3 appears later than the other three cohesin subunits, observing a substantial amount of SCC3 foci along AE/LEs from zygotene through pachytene, according with the SC assembly. There is no a functional analysis about the implication of this vegetal cohesin in SC formation and synapsis, but this sequential loading shows a possible change of cohesin complexes composition or organization at a meiotic stage which is key in the correct progression of synapsis. This non-homogenous 
timing and spatial localization of different cohesin proteins has been reported in other organisms such as C. elegans (Chan et al., 2003) or male grasshoppers (Valdeolmillos et al., 2007). Males of grasshoppers Locusta migratoria and Eyprepocnemis plorans species represent another cytological example of the contribution of cohesins to synapsis. In grasshoppers the SMC3 subunit appeared as a dotted signal in preleptotene to form continuous lines in leptotene, meanwhile the non-SMC subunits RAD21 and SA1 were not localized until zygotene and only on synapsed regions. This means that in grasshoppers the incorporation of non-SMC cohesins would be spatially and temporally concomitant with the progression of synapsis. In zygotene and pachytene SMC3 and RAD21 present a continuous and linear pattern, similar to what would be expected of AE/LEs proteins and both cohesin subunits present a complete colocalization until diplotene, coinciding with the stages of disassemble of SC. It is relevant that the single $X$ chromosome of grasshopper males, which remains unsynapsed, presents neither RAD21 nor SA1 during prophase I. Further than the possible implication of RAD21 and SA1 in the complete assembly of SC or vice-versa, these observations open new questions: Would this synapsis-dependent sequential loading of cohesin during prophase I have an effect on the distribution of cohesins in metaphase I? Could we talk about a presence of cohesin depending on the synaptic history of chromosomes? At any case, these kind of studies pointed not only that cohesin subunits can be loaded onto meiotic chromosomes at different time or as part of different complexes, but also relate the loading of specific cohesin subunits with the timing of AEs formation and SC assembly. The idea of specific synapsis cohesin complexes is also supported by the evidence that SMC1a is mainly located along synapsed regions in mice spermatocytes, whereas SMC3 subunit localizes along the synapsed and unsynased AEs (James et al., 2002), in front of SMC1 $\beta$ which is mainly required for sister chromatid cohesion (Revenkova, et al., 2004). In addition, Sycp3\% and Smc1 $\%$ single and double oocytes mice mutants show that both proteins contribute to meiotic chromosome axis organization (Novak et al., 2008). The authors propose a several layers axis association, which contributed to the formation of meiotic chromosome axes in an independent manner. The basic layer would be formed by the same proteins that form the mitotic chromosome axis, the scaffold proteins (Maeshima \& Laemmli, 2003). SMC1 $\beta$ would be part of the second layer, it contributes to axes length but is not essential (Revenkova, et al., 2004). Finally SYCP3 would represent the third layer as basic component of AE/LEs. Thus a cohesin axis would be defined as a base axis before the AE/LEs in mammals, a similar organization has been proposed in grasshoppers (Valdeolmillos, et al., 2007). Smc1 $\beta \%$ mice spermatocytes do not progress further than midpachytene and the cells present abnormalities in chromosome structure (Revenkova, et al., 2004). The analysis of SC proteins showed that the AEs were shortened, but the synapsis occurred between the 19 couples of homologous chromosomes. Thus, despite of the close relationship of the cohesins and SC proteins and the evident interdependence between both groups of proteins, there are examples in mice where the absence of a cohesin subunit does not inhibit the complete formation of SC, albeit its structure is compromised (Revenkova, et al., 2004, Xu, et al., 2005). This could be explaining due to the presence of different cohesin complexes in mammal meiotic cells (Revenkova \& Jessberger, 2005, Revenkova \& Jessberger, 2006, Suja \& Barbero, 2009) which could act in a redundancy manner. All these evidences suggest that the cohesins and specifically the SMC cohesin provide a basis for AE assembly. Based on the description of the new cohesin subunits and regarding to its role in SC formation and synapsis, diverse authors have develop models of incorporation of new cohesin complexes or replacement of specific cohesin subunits during the early prophase I that we summarize in figure 4. 


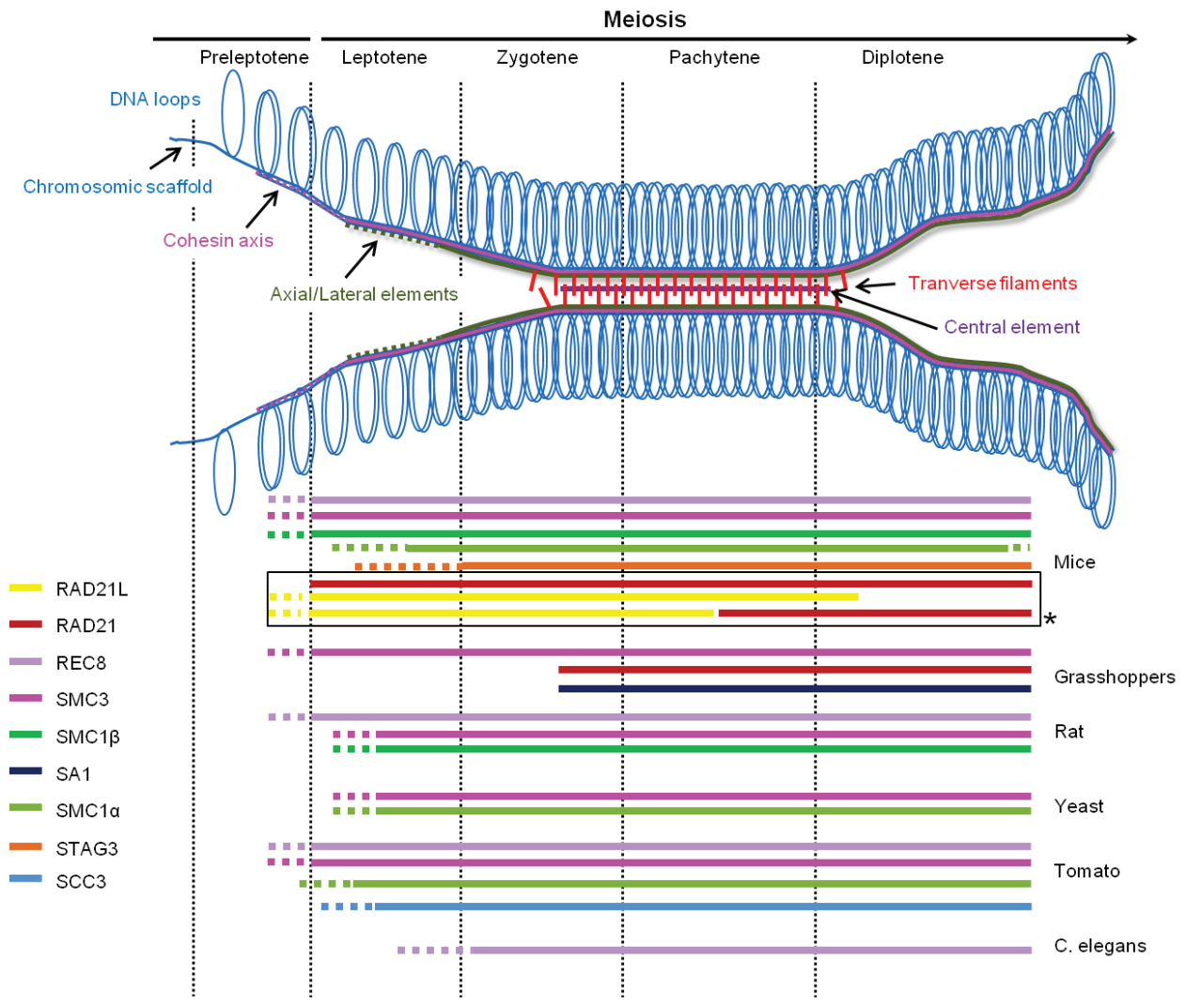

Fig. 4. Temporal meiotic appearance of cohesin subunits from preleptotene and its relationship with SC formation.

At the top of the figure a temporal line of early stages of meiosis progression is shown. The diagram positioned under this line is represented the cohesin axis formation and the SC assembly taking into account the data observed in mice. The blue lines represent the chromosomic scaffold and the blue circles are the chromatin loops. The pink color represents the cohesin organization, which is usually detected as a dotted pattern at preleptotene and from leptotene form axis that would the base for the AEs proteins. The $\mathrm{AE} / \mathrm{LEs}$ are represented in green, the FTs in red and the CE of SC in purple. At the bottom of the figure, under the diagram of SC assembly, the temporal localization of different cohesin subunits in different species is shown. The colour code for each cohesin subunit is situated at the left.

* This box shows the disagreement regarding to the RAD21 and RAD21L dynamic. See text for further detail.

In the nematode C. elegans, REC-8 and HIM-3, a component of meiotic chromosomes axes required for synapsis (Zetka et al., 1999), overlap during leptotene, zygotene and pachytene, suggesting that REC-8 is a component of AE/LEs (Pasierbek et al., 2001). SMC-1 
and SMC-3 loaded onto chromatin independently of REC-8 and SCC-3. On the other hand the depletion of $\operatorname{Rec}-8$ by RNAi did not cause change in SMC-1 or SMC-3 localization but a mislocalization of SCC-3 was detected (Chan, et al., 2003). The importance of REC-8 as an associated component of AEs in C. elegans derives from the evidence that this protein is presented along the axes of unsynapsed chromosomes and this meiosis-specific cohesin subunit seems to be necessary for the assembly of SC components such as HIM-3, SYP-1 and SYP-2 (Colaiacovo, 2006, MacQueen et al., 2002, Nabeshima et al., 2005, Pasierbek, et al., 2001). Moreover, the analysis of Rec-8 (RNAi) mutants showed that this protein is implicated in the chromosome pairing and SC assembly during leptotene/zygotene stage and the meiotic chromosomes are reorganized before diplotene into pachytene-like arrangement but they fail to achieve a normal lengthwise alignment (Chan, et al., 2003). Probably REC8 is the subunit of cohesin more widely studied in meiosis, it is a meiotic-specific cohesin variant of the subunit SCC1/RAD21. REC8 has orthologs in different organisms, it is present in mammals (Xu, et al., 2005), yeast (Klein, et al., 1999, Molnar, et al., 1995), plants (Qiao, et al., 2011, Zhang et al., 2006) and C. elegans (Pasierbek, et al., 2001). Although it has not been defined an obvious REC8 homologue in Drosophila melanogaster, C(2)M is a protein distantly related to REC8 which has not play a cohesion role but localized to LEs and interacts with SMC3 (Anderson et al., 2005). In rat spermatocytes the meiosis-specific REC8 protein was observed as axial structures during premeiotic $S$ phase, earlier than SMC1 $\beta$ and SMC3 which appeared during leptotene along with SYCP2 and SYCP3, suggesting an special role of REC8 in AEs formation (Eijpe, et al., 2003, Revenkova, et al., 2001). The meiocytes of males and females Rec 8 null mice do not complete the prophase I and presents SC assembly between sister chromatids ( $\mathrm{Xu}$, et al., 2005). Thus, in mammals REC8 seems to be necessary to the formation of SC between homologous chromosomes instead of the properly assembly of SC, albeit its structure is altered. Recently a new meiosis-specific SCC1 cohesin subunit has been identified in vertebrates, it is closely related to RAD21 and it has been named RAD21L (RAD21-like) (Gutierrez-Caballero, et al., 2011, Ishiguro, et al., 2011, Lee \& Hirano, 2011). RAD21L interacts with other cohesin subunits such as SMC1a/ $\beta$, SMC3 or STAG3 but does not interact with REC8, thus both kleisins subunits form distinct meiosis-specific cohesin complexes (Gutierrez-Caballero, et al., 2011, Ishiguro, et al., 2011). There is no agreement regarding to the localization of RAD21L from mid-pachytene/diplotene, thus meanwhile some authors ensure that RAD21L disappears from chromosomes axes at midpachytene when the SC is still formed (Lee \& Hirano, 2011), others have found that RAD21L is dissociated from AEs on autosomes in a progressive manner, during SC disassembly at diplotene (Herran, et al., 2011, Ishiguro, et al., 2011) and it is accumulated at centromeres until anaphase II (Herran, et al., 2011). Similarly, there are different results in relation with the coexistence of RAD21 and RAD21L complexes during early prophase I stages. Lee and Hirano (2011) ensure that RAD21L seems to replace RAD21 from leptotene, finding that RAD21L localizes along AE/LEs until pachytene, accompanying the SC formation and homologous synapsis. However, RAD21 has been previously detected by immunolocalization during leptotene, zygotene and pachytene in mouse spermatocytes by other authors (Parra, et al., 2004, Xu et al., 2004) and at least in the first case, the antibody used in Parra's et al., study does not cross-react with RAD21L as it is shown in Herran's et al., paper., suggesting the presence of both RAD21 and RAD21L at the same time. At any case REC8, RAD21 and RAD21L are detected in a mutually exclusive manner, forming part 
of different cohesin complexes. The definitive evidence to ensure that RAD21L is directly implicated in AEs formation and synapsis is the Rad21 $\mathrm{L}^{-1}$ male mouse which exhibits discontinuous AEs stretches and fails in homologous synapsis, moreover the mutants present defects in DSBs processing (Herran, et al., 2011). The RAD21L knockout males are sterile but females are fertile although develop age-dependent sterility is observed. On the other hand, there are evidences of the interaction of RAD21L and SYCP1, main component of TFs of SC (Meuwissen et al., 1992), and the centromere protein CENP-C (Ishiguro, et al., 2011, Lee \& Hirano, 2011). In a general manner, there is a rising common idea about the specific implication of RAD21L in pairing and the initiation of synapsis between homologous chromosomes (Herran, et al., 2011, Ishiguro, et al., 2011, Lee \& Hirano, 2011, Polakova et al., 2011). However, many questions are still open and new interesting doubts have been joined the fray regarding to the regulation of RAD21L cohesin complexes (Uhlmann, 2011).

In mouse testis the meiotic protein STAG3 was first identified as a stromalin member associated to SC (Pezzi, et al., 2000) and after that was described its participation in the cohesin complex and its specificity to cohesion of sister chromatid arms during first meiotic division (Prieto, et al., 2001), however the authors pointed that STAG3 could be a component of SC, being detectable on chromatin paralleling to AEs appearance. This is an interesting example because STAG3 is the fourth component of the cohesin complex, it is not a kleisin and does not interact with SMC proteins which might be the base of the cohesin axes formed during the early stage of prophase I. Thus in a general model it has been observed a correlation between the progression of AE/LEs formation and synapsis and the localization of several cohesin subunits. According to the studied organisms the localization of cohesin subunits during prophase I has been observed continuous or discontinuous; however this could be related with the preparation method or the meiotic stage. In any case, all cohesin subunit are associated with AE/LEs during prophase I. What we consider more relevant is the sequential loading of cohesins observed during the first stages of prophase I and how the appearance of some subunits seems to be closely related with the progression of $\mathrm{AE} / \mathrm{LEs}$ and SC formation and synapsis progression. In this sense, it is important to consider if the association of the cohesin subunits with the AE/LEs could be in an independent manner one to another. These cases would be possible only if we consider that in these species different cohesin complexes exist, as different author postulated before (Chan, et al., 2003, Eijpe, et al., 2003, Qiao, et al., 2011, Suja \& Barbero, 2009, Valdeolmillos, et al., 2007), being some of them more intimately related with the progression of synapsis or the SC formation. But then, we should think about if the cohesins loaded during early prophase I are really exerted a cohesin function or are related with AE/LEs formation and/or synapsis progression. Different analysis in mitotic cells showed that only the cohesins loaded during $S$ phase are effective in the cohesion of sister chromatids (Austin et al., 2009, Guacci, 2007), despite of evidences about new cohesion at DBSs point (Strom \& Sjogren, 2005). Generally, the SMC cohesins seems to be more closely related with the $\mathrm{AE} / \mathrm{LEs}$ formation, derivates from the evidences that this cohesin subunits are the base of the cohesin complexes then they would be the base of a cohesin axis and appear during the stages where SYCP2 and SYCP3 are incorporated or a bit early (Eijpe, et al., 2000, Klein, et al., 1999, Novak, et al., 2008, Qiao, et al., 2011, Revenkova, et al., 2001, Valdeolmillos, et al., 2007). However, the non-SMC proteins seem to have more specific roles before AEs 
formation (Eijpe, et al., 2003, Gutierrez-Caballero, et al., 2011, Ishiguro, et al., 2011, Molnar, et al., 1995) or during SC assembly (Valdeolmillos, et al., 2007). Especially we are thinking in the SCC1 subunits and all its variants, and then a cohesin complex would acquire a specific role depending on the SCC1 which is formed with. It is difficult to split out the study of cohesin distribution during first meiotic division and the function of SC as the physical connector of homologous chromosomes at prophase I. More and more the scientists notice that the cohesins present function or contribute to function that historically had been attributed to the SC or to specific SC proteins and different cohesin complexes acquire specific functions in meiosis.

\subsection{Cohesins and meiotic recombination}

The first evidence that sister chromatid cohesion is required for DNA damage repair was the observation that the expression of mutated cohesins or the deletion of some subunits cause hypersensitivity and fails in DNA repair after induced or spontaneous DSBs in somatic line (Birkenbihl and Subramani, 1992; Sonoda et al., 2001). Cohesin complexes are preferred loaded at intergenic sites (Lengronne et al., 2004) onto the replicating chromosomes during $S$ phase. However, now it is clear that in somatic cells the DNA damage induces the recruitment of cohesins after replication and lead to the formation of new cohesion (Strom and Sjogren, 2005), which is essential for DNA repair (Strom et al., 2004). Since the ability of SMC proteins to promote reannealing of complementary DNA strand was described, a role of cohesins in resolving DSBs was suggested (Jessberger et al., 1996). Different authors have studied and reviewed the role of cohesins in DSBs repair in S and G2 periods in mitotic cells (Cortes-Ledesma \& Aguilera, 2006; Nagao et al., 2004; Strom \& Sjogren, 2007; Watrin \& Peters, 2006), however, during meiosis the DSBs are programmed, in front of the spontaneous breaks that can alter the genome during the rest of the cell cycle. Basically mitotic/somatic and meiotic recombination have different purposes, thus whereas the meiotic recombination is initiated to generate a crossover $(\mathrm{CO})$ on each bivalent at least, the mitotic recombination is used to repair DNA damage to ensure the fidelity of DNA sequence and cell surveillance. This important difference affects the repair pathway (Andersen \& Sekelsky, 2010). We do not pretend to review all the literature regarding to the function of cohesin in all kinds of DNA damage, we will focus our attention in those cohesin subunits that have a specific role in meiotic DSBs and recombination.

Most of current models of meiotic recombination are based in the model that Szostak and colleagues proposed in yeast in 1983. This model is based on the generation of DSBs at early prophase I, the strand invasion at zygotene, the formation of double Holliday junction ( $\mathrm{dHJ}$ ) intermediate and its resolution at pachytene/diplotene. Obviously the repair mechanisms of DNA molecules act in an organized chromosome, where protein axial structures such as AEs and cohesin axis exist. The DSBs may be resolved toward CO between homologous chromatids or NCO (non-crossover), this decision can be made at different steps or repair pathway (see Heyer et al., 2010 for further details). Meiotic COs are essential for ensuring chromosome segregation. Chiasmata, points of genetic interchange between non-sister chromatids, keep the homologous chromosomes as a single structure after the disassembly of SC. Chiasmata and sister chromatid cohesion ensure the correct orientation of bivalents at metaphase I. Thus, in a similar way that fails in cohesion lead premature separation of 
chromatids, fails in meiotic recombination promote the generation of univalents at metaphase I. In both cases a high probability of aneuploidy exists. Meiotic recombination is initiated after a replication period, thus the sister chromatids are linked by cohesins when the recombination process begins. It has been established that cohesins are needed for the formation and stabilization of DNA interconnections (Buonomo et al., 2000; Klein et al., 1999).

Meiotic recombination begins via DSBs formation by the Topoisomerase II-like enzyme SPO11 (Grelon et al., 2001; Keeney et al., 1997). As consequence of SPO11 activity a great amount of DSBs are generated during early meiotic prophase I and most of them are repaired as NCO. Thus the cohesins take part in bivalent stabilization and recombination to ensure that the excess of programmed DSBs do not alter the chromosome organization. On the other hand specific roles of different cohesin subunits in DSBs formation and regulation have been also described. As we stated above the basic difference between meiotic and mitotic recombination lies in the generation of DSBs, thus SPO11 has a pivotal role in the activation of meiotic recombination machinery and the regulation of this enzyme is one of the most interesting topics of meiotic recombination analysis. SPO11 has the key to begin all the process of genetic exchange between non-homologous chromosomes. Different studies have shown a non-random distribution of meiotic DSBs (Baudat \& Nicolas, 1997; de Massy, 2003; de Massy et al., 1995; Gerton et al., 2000), giving raise to hot and cold-spots recombination sites. Different factors, as some histone variants (Buard et al., 2009) or the DNA sequence (Grey et al., 2009), determine and regulate the action of SPO11. In this context the cohesins have also been implicated. In budding yeast the initial centromeric entry of SPO11 depends on REC8 and this subunit of cohesin complex choreographs the distribution of SPO11 to DSBs sites (Kugou et al., 2009). On the other hand, in S. pombe, the Rec8 8 mutant shows a marked reduction of meiosis-specific DNA breakage by REC12 (the S. pombe SPO11 homologue) (Ellermeier \& Smith, 2005) and in C. elegans has been proposed that REC-8 could be implicated in limiting the activity of SPO-11 (Hayashi et al., 2007). However, whereas in S. cerevisiae Rec8 mutants the chromosome segregation is at random (Klein et al., 1999), similar mutants in S. pombe present a equational segregation of sister chromatids at anaphase I (Watanabe \& Nurse, 1999). These discordant results suggest that the regulation of meiotic cohesin complexes containing REC8 and its role in recombination depends on the species. After the formation of DSBs by SPO11, modifications on chromatin as the phosphorylation of histone variants $\mathrm{H} 2 \mathrm{AX}, \mathrm{H} 2 \mathrm{Av}$ and $\mathrm{H} 2 \mathrm{~B}$ occur (FernándezCapetillo et al., 2004; Madigan et al., 2002; Redon et al., 2002) and a cascade of repair proteins are loaded onto damage sites in order to restore the DNA properly. The first recombinases that bind to chromatin after DSBs are RAD51 and DMC1. The last one is a meiosis-specific protein. Usually the recruitment of recombinases has been associated to the AEs (Plug et al., 1998; Tarsounas et al., 1999), but the cohesin axis is also functional in recruiting DNA recombination proteins. This issue was observed in Sycp3\% mice spermatocytes, where the recombinase RAD51 is recruited in the absence of AEs (Yuan et al., 2000) suggesting a higher level of organization which is probably related to the cohesins. The resection of single-strand DNA allows the single-end invasion promoted by both recombinases RAD51 and DMC1 (Neale and Keeney, 2006; Shinohara and Shinohara, 2004). The extended invading strands are then processed to form CO or NCO. At this point the most of DBSs are resolved by Synthesis-Dependent Strand Annealing (SDSA) through NCO (Allers \& Lichten, 2001). Some points of strand invasion are stabilized to form a D loop and 
double Holliday junctions ( $\mathrm{dHJ}$ ) intermediate, which can be resolved through $\mathrm{CO}$ or $\mathrm{NCO}$ depending on the cleavage of $\mathrm{dHJ}$. The DSBs formation and the $\mathrm{CO} / \mathrm{NCO}$ decision are two relevant items in meiotic recombination studies. In mice, before the AEs formation a cohesin core is observed as we reviewed above, but the action of SPO11 is not required for the formation of cohesin cores as it was observed in Spo11\% spermatocytes, being SMC1a mostly associated to homologous or non-homologous synapsed regions meanwhile SMC3 localized both to AEs of unsynapsed and synapsed cores at arrested zygotene cells (James et al., 2002). In mammals, the absence of REC8 does not affect the timing of DSBs formation and the recruitment of the recombinases RAD51/DMC1, suggesting than DSBs and the early recombination events occur properly. But, the persistence of RAD51/DMC1 foci in Rec8\%mice spermatocytes and the absence of MLH1 foci might reflect the inability to repair the DSBs (Xu et al., 2005). MLH1 and MLH3 protein are implicated in resolution of recombination to chiasma (Hunter \& Borts, 1997; Wang et al., 1999). It is not clear if REC8 has a specific role in resolving the meiotic DNA damage or the persistence of unresolved DSBs is a consequence of that the $\operatorname{Rec} 8 \%$ cells do not reach the meiotic stage where the recombination resolution takes place. In this rodent REC8 seems to have a pivotal role in sister chromatid cohesion and synapsis but its relationship with recombination is not clear, despite of a small proportion of REC8 coprecipitate with RAD51/DMC1. Moreover a small proportion of RAD50 coimmunoprecipitate with REC8 from spermatocyte lysates but REC8 does not coprecipitate with RAD50 (Eijpe et al., 2003). RAD50, MRE11 and NBS1 proteins form the MRN complex which is implicated in the early response to DNA damage. The action of MRN complex is related to nuclease activity at the $5^{\prime}$ ends, releasing SPO11 from DNA (Lichten, 2001). After the action of MRN, RAD51 and DMC1 can bind to single-strand DNA. These results which relate REC8 with recombination repair proteins would indicate that protein complexes that contain both REC8 and RAD51/DMC1 and some RAD50 exist in spermatocytes (Eijpe et al., 2003). The authors proposed that after $S$ phase, cohesins would attract protein complexes that are involved in the early steps of homologous recombination. Recent results in yeast proposed that Rec8 could have a role in maintaining the homolog bias of recombination (Kim et al., 2010). In Rad $21 L^{-/}$mice spermatocytes an accumulation of unrepaired DSBs has been described, but the cells are arrested at zygotenelike stage (Herran et al., 2011). Although, in sight of the cytological results of appearance and disappearance of RAD21L in wild type mice, a role in meiotic recombination has been suggested for this cohesin subunit (Herran et al., 2011; Ishiguro et al., 2011), deeply studies are needed to corroborate the implication of RAD21L in the processing of recombination intermediates. However, in this context we might probably talk about a role of SMC1 $\beta$ in recombination. Initially this protein was found at bridges between homologous AEs, and it was supposed that these represented the chiasmata sites (Revenkova et al., 2001). In Smc1 $\beta-$ spermatocytes early markers of recombination as RAD51 and $\gamma-\mathrm{H} 2 \mathrm{AX}$ localize properly. The cells progress through mid-pachytene and MLH1 and MLH3 foci were not detected in males, additionally the Smc1 $\beta^{-}$oocytes develop further and also fail to form the normal number of MLH1 foci (Revenkova et al., 2004). Probably the effects observing in cohesin mutants regarding to recombination proteins could be explain due to improper sister chromatid cohesion, an incorrect formation of AEs or synaptic fails. Perhaps we have to analyze the relationship between cohesin and meiotic recombination in a cohesin-dependent chromatin organization. An example is found in S. pombe, in this organism Rec8 and Rec11, meiosis-specific cohesin subunits, are essential for DSBs only in some regions of the genome (Ellermeier \& Smith, 2005). On the other hand the loading of Rec25 and Rec27, two 
recombination proteins in yeast, depends on the previous incorporation of Rec8 (Davis et al., 2008). This issue could be explained because of Rec8 is required for the normal chromosome compaction during meiotic prophase I (Ding et al., 2006), thus it has been proposed that the regional effect on DSBs production might be related to the meiotic chromosomal organization formed by the cohesins (Davis et al., 2008). Thus the role of cohesins in meiotic recombination should be at different levels, chromosomal organization, providing the proximity between sister chromatid to ensure a correct repair with an undamaged template and as individual proteins that form complexes with recombination proteins.

Finally we would like to comment two interesting cytological examples of the relationship between cohesin axis development, synapsis and recombination. The males of Stethophyma grossum exhibit a delay in cohesin axis formation in the eight longest bivalents of its complement and in the single $X$ chromosome (Calvente et al., 2005). These regions remain unsynapsed, presenting three different synaptic situations: an unsynapsed sex chromosome, three bivalents with complete synapsis and eight bivalents with incomplete synapsis (Jones, 1973; Wallace \& Jones, 1978). In this species the DSBs and the recruitment of first recombinases occur before the beginning of synapsis, detecting RAD51 foci over the cohesin axis at leptotene. But the most interesting event is that $\gamma-\mathrm{H} 2 \mathrm{AX}$ and RAD51 foci are polarized to the nuclear region where the cohesin axis are formed in advanced and these regions correspond with the ulterior synapsed chromosomal regions. Thus, those chromosomal regions that at leptotene do not exhibit a formed cohesin axes do not present DSBs and then do not recruit RAD51 (Calvente et al., 2005). A similar case has been observed in Paratettix meriodinalis, another grasshopper species with an incomplete synapsis pattern. The spermatocytes of this species show a polarization of cohesin axes maturation and the initiation of meiotic recombination, suggesting that the early development of cohesin axis would drive the loading of recombination machinery (Viera et al., 2009b). Obviously the study of AEs proteins would clarify the real relationship among SC formation, cohesin axis development and recombination in this special organism but these examples show the relevance of a cohesin axis formed by at least SMC proteins not only in the beginning of meiotic recombination but also in synapsis progression.

\section{Cohesins and cohesin-regulators in human cancer and cohesinophaties}

As we commented before, dysfunction of chromosome cohesion during meiosis frequently gives fertility problems. However, now we know that cohesins participate in other important cell processes, such as mitotic DNA damage repair and control of gene expression. One of the most surprising findings was the discovery of a link between cohesin mutations and human diseases. Two groups, (Krantz et al., 2004, Tonkin et al., 2004), found that the Nipbl gene, the homologue to yeast $S c c 2$ adherin gene, is mutated in the human CdLS (OMIM: 122470, 300590, 610759). This pathology is a multiple neuro-developmental disorder characterized by facial dysmorphisms, mental retardation, growth delay, and upper limb abnormalities. Subsequent studies of several cases of this syndrome showed that mutations in SMC1a and SMC3 (Musio et al., 2006, and Deardorff et al., 2007) cause a mild variant of CdLS. Roberts syndrome/SC phocomelia (RBS; OMIM: 268300) is an autosomal recessive disorder phenotypically related to CdLS; RBS patients present craniofacial abnormalities, growth retardation, and limb reduction. Cells from RBS patients show a lack 
of cohesion at the heterochromatic regions around the centromeres and at the $Y$ chromosome long arm (Van Den Verg and Francke, 1993). It has been described that RBS is caused by mutations in ESCO2 gene (Vega et al., 2005) and analyses of different mutations in RBS patients pointed to the loss of ESCO2 acetyltransferase activity as the molecular mechanism involved in RBS pathology (Gordillo et al., 2008). On the other hand, in the last years have been published different studies and experimental data that links cancer development with disorders in the core cohesin subunit and cohesin- interacting proteins genes. Although, we do not mind to review this field here, the following paragraphs reveal the importance of cohesins, including meiotic-specific cohesin genes in tumorogenesis. The study of 11 somatic mutations in 132 human colorectal cancers identified 6 of them mapping to 3 cohesin, SMC1a,SMC3 and STAG3, genes and 4 to a cohesin-regulator SCC2 gene (Barber et al., 2008). Colorectal cancer cells are characterized by chromosomal instability, resulting in chromosome gain or loss. It is possible to argue that abnormal cohesin pathway activity leads to chromosome missegregation and chromosome instability. This hypothesis is supported by the observation that colorectal cancer cells exhibit up to 100-fold higher rates of missegregation than normal cells (Lengauer et al., 1997). In adittion, using a microcell mediated chromosome transfer and expression microarray analysis the cohesin STAG3 gene was identified as one of the nine genes associated with functional suppression of tumorogenicity in ovarian cancer cell lines (AIFM2, AKTIP, AXIN2, CASP5, FILIP1L, RBBP8, RGC32, RUVBL1 and STAG3) and as a candidate gene associated with risk and development of epithelial ovarian cancer (Notaridou et al., 2011). The future research on the molecular mechanisms surrounding the cell regulation of cohesin is crucial to understand the relationship between the cohesin-interacting proteins and cohesin post-translational modification with developmental alterations and cancer. These studies probably will help to understand the relationships between this interesting ring protein complex and the formation/development of tumors in humans.

\section{Conclusions}

In the late 90's, cohesins were discovered and characterized are the main actors in controlling the sister chromatid joint until the chromosomic segregation. This important issue ensures a correct distribution of chromosomes to daughter cells and then the viability and continuity of all organisms. Undoubtedly the cohesion regulation leads the chromosomic segregation in mitosis and meiosis. However, whereas a correct regulation of cohesion in mitosis is crucial for development, in meiosis this process is vital for the fertility of the individuals. The complexity of meiosis arises from the necessity of generate haploids cells and the magic of this type of cell division is that all the daughters cells are different among them and to the mother cell. In order to carry out this great objective, the homologous chromosomes form bivalents, recombine, organize a complex protein structure between them, the SC, and go through two consecutive segregations. In this context the cohesion and the cohesin complex in meiosis present different specializations such as meiosis-specific cohesin subunits or a strict regulation of the release of arm and centromeric cohesion during both chromosomic segregations. As an example of this complexity, nowadays four meiosis-specific cohesin subunits have been identified in mice: SMC1 $\beta$, STAG3, REC8 and RAD21L. These subunits do not exclude the presence of other mitotic 
proteins, forming then a high number of different cohesin complexes. However, further than the role of cohesin complex in cohesion, all the specializations observed in meiosis seem to have an effect on functions of the cohesins. In this scenario we are now discovering the action of this fascinating group of proteins in the formation of AE/LEs, the progression of synapsis, the formation of programmed DSBs and the regulation of gene expression in meiosis. In a same way, we begin to understand the role of cohesins in developmental diseases and cancer. It have been identifying a growing number of proteins that interact with the cohesin complex and modulate the dynamics of cohesins and its binding to chromatin. Since the cohesins do not act in a single manner but they need different proteins to regulate their action, the cohesins-regulators have reached the attention of the scientific community. In addition, today we know that mutations in genes encoding cohesin regulators could give pathological conditions in humans. Update we do not know meiosisspecific regulators, but the action of the cohesin-interacting proteins must be regulated in a meiosis-specific manner and probably there are meiotic factors, which are waiting to be discovered. Many doubts are still unresolved and many doubts will appear later, but at any case we cannot study the cohesion and the cohesins as a single concept but a complex process and a versatile group of proteins which are implicated in the correct progress of the cell cycle in a global manner.

\section{Acknowledgments}

We thank Dr. Mónica Pradillo for her sincere and critical comments. We apologize to all colleagues whose important contributions have not been referenced due to space restrictions. This work was supported by the Spanish Ministerio de Ciencia e Innovación (grant BFU2009-08975/BMC) and CSIC (grant PIE-201120E020).

\section{References}

Allers, T. \& Lichten, M. (2001). Differential timing and control of noncrossover and crossover recombination during meiosis. Cell. Vol.106, No.1, pp.47-57, ISSN:00928674

Andersen, S.L. \& Sekelsky, J. (2010). Meiotic versus mitotic recombination: two different routes for double-strand break repair: the different functions of meiotic versus mitotic DSB repair are reflected in different pathway usage and different outcomes. Bioessays. Vol.32, No.12, pp.1058-1066, ISSN:1521-1878

Anderson, L.K., Royer, S.M., Page, S.L., McKim, K.S., Lai, A., Lilly, M.A. \& Hawley, R.S. (2005). Juxtaposition of C(2)M and the transverse filament protein $C(3) G$ within the central region of Drosophila synaptonemal complex. Proc Natl Acad Sci U S A. Vol.102, No.12, pp.4482-4487, ISSN:0027-8424

Austin, C., Novikova, N., Guacci, V. \& Bellini, M. (2009). Lampbrush chromosomes enable study of cohesin dynamics. Chromosome Res. Vol.17, No.2, pp.165-184, ISSN:15736849

Barber, T.D., McManus, K., Yuen, K.W., Reis, M., Parmigiani, G., Shen, D., Barrett, I., Nouhi, Y., Spencer, F., Markowitz, S., Velculescu, V.E., Kinzler, K.W., Vogelstein, B., Lengauer, C. \& Hieter, P. (2008). Chromatid cohesion defects may underlie 
chromosome instability in human colorectal cancers. Proc Natl Acad Sci U S A. Vol.105, No.9, pp.3443-3448, ISSN:1091-6490

Baudat, F. \& Nicolas, A. (1997). Clustering of meiotic double-strand breaks on yeast chromosome III. Proc Natl Acad Sci U S A. Vol.94, No.10, pp.5213-5218, ISSN:00278424

Beckouet, F., Hu, B., Roig, M.B., Sutani, T., Komata, M., Uluocak, P., Katis, V.L., Shirahige, K. \& Nasmyth, K. (2010). An Smc3 acetylation cycle is essential for establishment of sister chromatid cohesion. Mol Cell. Vol.39, No.5, pp.689-699, ISSN:1097-4164

Birkenbihl, R.P. \& Subramani, S. (1992). Cloning and characterization of rad21 an essential gene of Schizosaccharomyces pombe involved in DNA double-strand-break repair. Nucleic Acids Res. Vol.20, No.24, pp.6605-6611, ISSN:0305-1048

Borges, V., Lehane, C., Lopez-Serra, L., Flynn, H., Skehel, M., Rolef Ben-Shahar, T. \& Uhlmann, F. (2010). Hos1 deacetylates Smc3 to close the cohesin acetylation cycle. Mol Cell. Vol.39, No.5, pp.677-688, ISSN:1097-4164.

Buard, J., Barthes, P., Grey, C. \& de Massy, B. (2009). Distinct histone modifications define initiation and repair of meiotic recombination in the mouse. EMBO J. Vol.28, No.17, pp.2616-2624, ISSN:1460-2075

Buonomo, S.B., Clyne, R.K., Fuchs, J., Loidl, J., Uhlmann, F. \& Nasmyth, K. (2000). Disjunction of homologous chromosomes in meiosis I depends on proteolytic cleavage of the meiotic cohesin Rec8 by separin. Cell. Vol.103, No.3, pp.387-398.

Calvente, A., Viera, A., Page, J., Parra, M.T., Gomez, R., Suja, J.A., Rufas, J.S. \& Santos, J.L. (2005). DNA double-strand breaks and homology search: inferences from a species with incomplete pairing and synapsis. J Cell Sci. Vol.118, No.Pt 13, pp.2957-2963

Carramolino, L., Lee, B.C., Zaballos, A., Peled, A., Barthelemy, I., Shav-Tal, Y., Prieto, I., Carmi, P., Gothelf, Y., Gonzalez de Buitrago, G., Aracil, M., Marquez, G., Barbero, J.L. \& Zipori, D. (1997). SA-1, a nuclear protein encoded by one member of a novel gene family: molecular cloning and detection in hemopoietic organs. Gene. Vol.195, No.2, pp.151-159, ISSN:0378-1119

Ciosk, R., Zachariae, W., Michaelis, C., Shevchenko, A., Mann, M. \& Nasmyth, K. (1998). An ESP1/PDS1 complex regulates loss of sister chromatid cohesion at the metaphase to anaphase transition in yeast. Cell. Vol.93, No.6, pp.1067-1076, ISSN:0092-8674

Ciosk, R., Shirayama, M., Shevchenko, A., Tanaka, T., Toth, A. \& Nasmyth, K. (2000). Cohesin's binding to chromosomes depends on a separate complex consisting of Scc2 and Scc4 proteins. Mol Cell. Vol.5, No.2, pp.243-254, ISSN:1097-2765

Colaiacovo, M.P. (2006). The many facets of SC function during C. elegans meiosis. Chromosoma. Vol.115, No.3, pp.195-211, ISSN:0009-5915

Cortes-Ledesma, F. \& Aguilera, A. (2006). Double-strand breaks arising by replication through a nick are repaired by cohesin-dependent sister-chromatid exchange. EMBO Rep. Vol.7, No.9, pp.919-926, ISSN:1469-221X

Chan, R.C., Chan, A., Jeon, M., Wu, T.F., Pasqualone, D., Rougvie, A.E. \& Meyer, B.J. (2003). Chromosome cohesion is regulated by a clock gene paralogue TIM-1. Nature. Vol.423, No.6943, pp.1002-1009,

Chien, R., Zeng, W., Kawauchi, S., Bender, M.A., Santos, R., Gregson, H.C., Schmiesing, J.A., Newkirk, D.A., Kong, X., Ball, A.R., Jr., Calof, A.L., Lander, A.D., Groudine, M.T. \& Yokomori, K. (2011). Cohesin mediates chromatin interactions that regulate 
mammalian beta-globin expression. J Biol Chem. Vol.286, No.20, pp.17870-17878, ISSN:1083-351X

Davis, L., Rozalen, A.E., Moreno, S., Smith, G.R. \& Martin-Castellanos, C. (2008). Rec25 and Rec27, novel linear-element components, link cohesin to meiotic DNA breakage and recombination. Curr Biol. Vol.18, No.11, pp.849-854, ISSN:0960-9822

de Massy, B., Rocco, V. \& Nicolas, A. (1995). The nucleotide mapping of DNA double-strand breaks at the CYS3 initiation site of meiotic recombination in Saccharomyces cerevisiae. EMBO J. Vol.14, No.18, pp.4589-4598, ISSN:0261-4189

de Massy, B. (2003). Distribution of meiotic recombination sites. Trends Genet. Vol.19, No.9, pp.514-522, ISSN:0168-9525

Deardorff, M.A., Kaur, M., Yaeger, D., Rampuria, A., Korolev, S., Pie, J., Gil-Rodriguez, C., Arnedo, M., Loeys, B., Kline, A.D., Wilson, M., Lillquist, K., Siu, V., Ramos, F.J., Musio, A., Jackson, L.S., Dorsett, D. \& Krantz, I.D. (2007). Mutations in cohesin complex members SMC3 and SMC1A cause a mild variant of cornelia de Lange syndrome with predominant mental retardation. Am J Hum Genet. Vol.80, No.3, pp.485-494, ISSN:0002-9297

Diaz-Martinez, L.A., Gimenez-Abian, J.F. \& Clarke, D.J. (2007). Regulation of centromeric cohesion by sororin independently of the APC/C. Cell Cycle. Vol.6, No.6, pp.714724, ISSN:1551-4005

Ding, D.Q., Sakurai, N., Katou, Y., Itoh, T., Shirahige, K., Haraguchi, T. \& Hiraoka, Y. (2006). Meiotic cohesins modulate chromosome compaction during meiotic prophase in fission yeast. J Cell Biol. Vol.174, No.4, pp.499-508, ISSN:0021-9525

Dorsett, D. (2011). Cohesin: genomic insights into controlling gene transcription and development. Curr Opin Genet Dev. Vol.21, No.2, pp.199-206, ISSN:1879-0380

Eijpe, M., Heyting, C., Gross, B. \& Jessberger, R. (2000). Association of mammalian SMC1 and SMC3 proteins with meiotic chromosomes and synaptonemal complexes. J Cell Sci. Vol.113 ( Pt 4), pp.673-682

Eijpe, M., Offenberg, H., Jessberger, R., Revenkova, E. \& Heyting, C. (2003). Meiotic cohesin REC8 marks the axial elements of rat synaptonemal complexes before cohesins SMC1beta and SMC3. J Cell Biol. Vol.160, No.5, pp.657-670

Ellermeier, C. \& Smith, G.R. (2005). Cohesins are required for meiotic DNA breakage and recombination in Schizosaccharomyces pombe. Proc Natl Acad Sci U S A. Vol.102, No.31, pp.10952-10957, ISSN:0027-8424

Fernandez-Capetillo, O., Mahadevaiah, S.K., Celeste, A., Romanienko, P.J., Camerini-Otero, R.D., Bonner, W.M., Manova, K., Burgoyne, P. \& Nussenzweig, A. (2003). H2AX is required for chromatin remodeling and inactivation of sex chromosomes in male mouse meiosis. Dev Cell. Vol.4, No.4, pp.497-508,

Fernández-Capetillo, O., Lee, A., Nussenzweig, M. \& Nussenzweig, A. (2004). H2AX: the histone guardian of the genome. DNA Repair (Amst). Vol.3, No.8-9, pp.959-967

Gandhi, R., Gillespie, P.J. \& Hirano, T. (2006). Human Wapl is a cohesin-binding protein that promotes sister-chromatid resolution in mitotic prophase. Curr Biol. Vol.16, No.24, pp.2406-2417, ISSN:0960-9822

Garcia-Cruz, R., Brieno, M.A., Roig, I., Grossmann, M., Velilla, E., Pujol, A., Cabero, L., Pessarrodona, A., Barbero, J.L. \& Garcia Caldes, M. (2010). Dynamics of cohesin proteins REC8, STAG3, SMC1 beta and SMC3 are consistent with a role in sister 
chromatid cohesion during meiosis in human oocytes. Hum Reprod. Vol.25, No.9, pp.2316-2327, ISSN:1460-2350

Gerton, J.L., DeRisi, J., Shroff, R., Lichten, M., Brown, P.O. \& Petes, T.D. (2000). Global mapping of meiotic recombination hotspots and coldspots in the yeast Saccharomyces cerevisiae. Proc Natl Acad Sci U S A. Vol.97, No.21, pp.11383-11390, ISSN:0027-8424

Gomez, R., Valdeolmillos, A., Parra, M.T., Viera, A., Carreiro, C., Roncal, F., Rufas, J.S., Barbero, J.L. \& Suja, J.A. (2007). Mammalian SGO2 appears at the inner centromere domain and redistributes depending on tension across centromeres during meiosis II and mitosis. EMBO Rep. Vol.8, No.2, pp.173-180,

Gordillo, M., Vega, H., Trainer, A.H., Hou, F., Sakai, N., Luque, R., Kayserili, H., Basaran, S., Skovby, F., Hennekam, R.C., Uzielli, M.L., Schnur, R.E., Manouvrier, S., Chang, S., Blair, E., Hurst, J.A., Forzano, F., Meins, M., Simola, K.O., Raas-Rothschild, A., Schultz, R.A., McDaniel, L.D., Ozono, K., Inui, K., Zou, H. \& Jabs, E.W. (2008). The molecular mechanism underlying Roberts syndrome involves loss of ESCO2 acetyltransferase activity. Hum Mol Genet. Vol.17, No.14, pp.2172-2180, ISSN:14602083

Grelon, M., Vezon, D., Gendrot, G. \& Pelletier, G. (2001). AtSPO11-1 is necessary for efficient meiotic recombination in plants. EMBO J. Vol.20, No.3, pp.589-600, ISSN:0261-4189

Grey, C., Baudat, F. \& de Massy, B. (2009). Genome-wide control of the distribution of meiotic recombination. PLoS Biol. Vol.7, No.2, pp.e35, ISSN:1545-7885

Gruber, S., Haering, C.H. \& Nasmyth, K. (2003). Chromosomal cohesin forms a ring. Cell. Vol.112, No.6, pp.765-777, ISSN:0092-8674

Guacci, V. (2007). Sister chromatid cohesion: the cohesin cleavage model does not ring true. Genes Cells. Vol.12, No.6, pp.693-708, ISSN:1356-9597

Gutierrez-Caballero, C., Herran, Y., Sanchez-Martin, M., Suja, J.A., Barbero, J.L., Llano, E. \& Pendas, A.M. (2011). Identification and molecular characterization of the mammalian alpha-kleisin RAD21L. Cell Cycle. Vol.10, No.9, pp.1477-1487, ISSN:1551-4005

Haering, C.H., Lowe, J., Hochwagen, A. \& Nasmyth, K. (2002). Molecular architecture of SMC proteins and the yeast cohesin complex. Mol Cell. Vol.9, No.4, pp.773-788

Hauf, S., Roitinger, E., Koch, B., Dittrich, C.M., Mechtler, K. \& Peters, J.M. (2005). Dissociation of cohesin from chromosome arms and loss of arm cohesion during early mitosis depends on phosphorylation of SA2. PLoS Biol. Vol.3, No.3, pp.e69

Hayashi, M., Chin, G.M. \& Villeneuve, A.M. (2007). C. elegans germ cells switch between distinct modes of double-strand break repair during meiotic prophase progression. PLoS Genet. Vol.3, No.11, pp.e191, ISSN:1553-7404

Herran, Y., Gutierrez-Caballero, C., Sanchez-Martin, M., Hernandez, T., Viera, A., Barbero, J.L., de Alava, E., de Rooij, D.G., Suja, J.A., Llano, E. \& Pendas, A.M. (2011). The cohesin subunit RAD21L functions in meiotic synapsis and exhibits sexual dimorphism in fertility. EMBO J:1460-2075

Heyer, W.D., Ehmsen, K.T. \& Liu, J. (2010). Regulation of homologous recombination in eukaryotes. Annu Rev Genet. Vol.44, pp.113-139, ISSN:1545-2948

Hogarth, C.A., Mitchell, D., Evanoff, R., Small, C. \& Griswold, M. (2011). Identification and expression of potential regulators of the mammalian mitotic-to-meiotic transition. Biol Reprod. Vol.84, No.1, pp.34-42, ISSN:1529-7268 
Hou, F. \& Zou, H. (2005). Two human orthologues of Eco1/Ctf7 acetyltransferases are both required for proper sister-chromatid cohesion. Mol Biol Cell. Vol.16, No.8, pp.39083918, ISSN:1059-1524

Hunter, N. \& Borts, R.H. (1997). Mlh1 is unique among mismatch repair proteins in its ability to promote crossing-over during meiosis. Genes Dev. Vol.11, No.12, pp.15731582

Ishiguro, K., Kim, J., Fujiyama-Nakamura, S., Kato, S. \& Watanabe, Y. (2011). A new meiosis-specific cohesin complex implicated in the cohesin code for homologous pairing. EMBO Rep. Vol.12, No.3, pp.267-275, ISSN:1469-3178

James, R.D., Schmiesing, J.A., Peters, A.H., Yokomori, K. \& Disteche, C.M. (2002). Differential association of SMC1alpha and SMC3 proteins with meiotic chromosomes in wild-type and SPO11-deficient male mice. Chromosome Res. Vol.10, No.7, pp.549-560, ISSN:0967-3849

Jessberger, R., Riwar, B., Baechtold, H. \& Akhmedov, A.T. (1996). SMC proteins constitute two subunits of the mammalian recombination complex RC-1. EMBO J. Vol.15, No.15, pp.4061-4068, ISSN:0261-4189

Jin, H., Guacci, V. \& Yu, H.G. (2009). Pds5 is required for homologue pairing and inhibits synapsis of sister chromatids during yeast meiosis. J Cell Biol. Vol.186, No.5, pp.713725, ISSN:1540-8140

Jones, G.H. (1973). Light and electron microscope studies of chromosome pairing in relation to chiasma localisation in Stethophyma grossum (Orthoptera: Acrididae). Chromosoma. Vol.42, No.2, pp.145-162

Keeney, S., Giroux, C.N. \& Kleckner, N. (1997). Meiosis-specific DNA double-strand breaks are catalyzed by Spo11, a member of a widely conserved protein family. Cell. Vol.88, No.3, pp.375-384

Khalil, A.M., Boyar, F.Z. \& Driscoll, D.J. (2004). Dynamic histone modifications mark sex chromosome inactivation and reactivation during mammalian spermatogenesis. Proc Natl Acad Sci U S A. Vol.101, No.47, pp.16583-16587

Kim, B.J., Kang, K.M., Jung, S.Y., Choi, H.K., Seo, J.H., Chae, J.H., Cho, E.J., Youn, H.D., Qin, J. \& Kim, S.T. (2008). Esco2 is a novel corepressor that associates with various chromatin modifying enzymes. Biochem Biophys Res Commun. Vol.372, No.2, pp.298304, ISSN:1090-2104

Kim, K.P., Weiner, B.M., Zhang, L., Jordan, A., Dekker, J. \& Kleckner, N. (2010). Sister cohesion and structural axis components mediate homolog bias of meiotic recombination. Cell. Vol.143, No.6, pp.924-937:1097-4172

Kitajima, T.S., Kawashima, S.A. \& Watanabe, Y. (2004). The conserved kinetochore protein shugoshin protects centromeric cohesion during meiosis. Nature. Vol.427, No.6974, pp.510-517

Kitajima, T.S., Sakuno, T., Ishiguro, K., Iemura, S., Natsume, T., Kawashima, S.A. \& Watanabe, Y. (2006). Shugoshin collaborates with protein phosphatase $2 \mathrm{~A}$ to protect cohesin. Nature. Vol.441, No.7089, pp.46-52, ISSN:1476-4687

Klein, F., Mahr, P., Galova, M., Buonomo, S.B., Michaelis, C., Nairz, K. \& Nasmyth, K. (1999). A central role for cohesins in sister chromatid cohesion, formation of axial elements, and recombination during yeast meiosis. Cell. Vol.98, No.1, pp.91-103

Krantz, I.D., McCallum, J., DeScipio, C., Kaur, M., Gillis, L.A., Yaeger, D., Jukofsky, L., Wasserman, N., Bottani, A., Morris, C.A., Nowaczyk, M.J., Toriello, H., Bamshad, 
M.J., Carey, J.C., Rappaport, E., Kawauchi, S., Lander, A.D., Calof, A.L., Li, H.H., Devoto, M. \& Jackson, L.G. (2004). Cornelia de Lange syndrome is caused by mutations in NIPBL, the human homolog of Drosophila melanogaster Nipped-B. Nat Genet. Vol.36, No.6, pp.631-635, ISSN:1061-4036

Kugou, K., Fukuda, T., Yamada, S., Ito, M., Sasanuma, H., Mori, S., Katou, Y., Itoh, T., Matsumoto, K., Shibata, T., Shirahige, K. \& Ohta, K. (2009). Rec8 guides canonical Spo11 distribution along yeast meiotic chromosomes. Mol Biol Cell. Vol.20, No.13, pp.3064-3076, ISSN:1939-4586

Kuroda, M., Oikawa, K., Ohbayashi, T., Yoshida, K., Yamada, K., Mimura, J., Matsuda, Y., Fujii-Kuriyama, Y. \& Mukai, K. (2005). A dioxin sensitive gene, mammalian WAPL, is implicated in spermatogenesis. FEBS Lett. Vol.579, No.1, pp.167-172, ISSN:00145793

Lafont, A.L., Song, J. \& Rankin, S. (2010). Sororin cooperates with the acetyltransferase Eco2 to ensure DNA replication-dependent sister chromatid cohesion. Proc Natl Acad Sci U S A. Vol.107, No.47, pp.20364-20369, ISSN:1091-6490

Lee, J. \& Hirano, T. (2011). RAD21L, a novel cohesin subunit implicated in linking homologous chromosomes in mammalian meiosis. J Cell Biol. Vol.192, No.2, pp.263276, ISSN:1540-8140

Lengauer, C., Kinzler, K.W. \& Vogelstein, B. (1997). DNA methylation and genetic instability in colorectal cancer cells. Proc Natl Acad Sci U S A. Vol.94, No.6, pp.2545-2550, ISSN:0027-8424

Lengronne, A., Katou, Y., Mori, S., Yokobayashi, S., Kelly, G.P., Itoh, T., Watanabe, Y., Shirahige, K. \& Uhlmann, F. (2004). Cohesin relocation from sites of chromosomal loading to places of convergent transcription. Nature. Vol.430, No.6999, pp.573-578, ISSN:1476-

Lichten, M. (2001). Meiotic recombination: breaking the genome to save it. Curr Biol. Vol.11, No.7, pp.R253-256

Lin, W., Jin, H., Liu, X., Hampton, K. \& Yu, H.G. (2011). Scc2 regulates gene expression by recruiting cohesin to the chromosome as a transcriptional activator during yeast meiosis. Mol Biol Cell. Vol.22, No.12, pp.1985-1996, ISSN:1939-4586

Losada, A., Hirano, M. \& Hirano, T. (1998). Identification of Xenopus SMC protein complexes required for sister chromatid cohesion. Genes Dev. Vol.12, No.13, pp.1986-1997

Losada, A., Yokochi, T., Kobayashi, R. \& Hirano, T. (2000). Identification and characterization of SA/Scc3p subunits in the Xenopus and human cohesin complexes. J Cell Biol. Vol.150, No.3, pp.405-416

Losada, A., Yokochi, T. \& Hirano, T. (2005). Functional contribution of Pds5 to cohesinmediated cohesion in human cells and Xenopus egg extracts. J Cell Sci. Vol.118, No.Pt 10, pp.2133-2141, ISSN:0021-9533

Llano, E., Gomez, R., Gutierrez-Caballero, C., Herran, Y., Sanchez-Martin, M., VazquezQuinones, L., Hernandez, T., de Alava, E., Cuadrado, A., Barbero, J.L., Suja, J.A. \& Pendas, A.M. (2008). Shugoshin-2 is essential for the completion of meiosis but not for mitotic cell division in mice. Genes Dev. Vol.22, No.17, pp.2400-2413, ISSN:08909369 
MacQueen, A.J., Colaiacovo, M.P., McDonald, K. \& Villeneuve, A.M. (2002). Synapsisdependent and -independent mechanisms stabilize homolog pairing during meiotic prophase in C. elegans. Genes Dev. Vol.16, No.18, pp.2428-2442, ISSN:0890-9369

Madigan, J.P., Chotkowski, H.L. \& Glaser, R.L. (2002). DNA double-strand break-induced phosphorylation of Drosophila histone variant H2Av helps prevent radiationinduced apoptosis. Nucleic Acids Res. Vol.30, No.17, pp.3698-3705

Maeshima, K. \& Laemmli, U.K. (2003). A two-step scaffolding model for mitotic chromosome assembly. Dev Cell. Vol.4, No.4, pp.467-480

Mahadevaiah, S.K., Turner, J.M., Baudat, F., Rogakou, E.P., de Boer, P., Blanco-Rodriguez, J., Jasin, M., Keeney, S., Bonner, W.M. \& Burgoyne, P.S. (2001). Recombinational DNA double-strand breaks in mice precede synapsis. Nat Genet. Vol.27, No.3, pp.271-276

Meuwissen, R.L., Offenberg, H.H., Dietrich, A.J., Riesewijk, A., van Iersel, M. \& Heyting, C. (1992). A coiled-coil related protein specific for synapsed regions of meiotic prophase chromosomes. EMBO J. Vol.11, No.13, pp.5091-5100, ISSN:0261-4189

Michaelis, C., Ciosk, R. \& Nasmyth, K. (1997). Cohesins: chromosomal proteins that prevent premature separation of sister chromatids. Cell. Vol.91, No.1, pp.35-45,

Miyazaki, W.Y. \& Orr-Weaver, T.L. (1994). Sister-chromatid cohesion in mitosis and meiosis. Annu Rev Genet. Vol.28, pp.167-187

Moldovan, G.L., Pfander, B. \& Jentsch, S. (2006). PCNA controls establishment of sister chromatid cohesion during S phase. Mol Cell. Vol.23, No.5, pp.723-732, ISSN:10972765

Molnar, M., Bahler, J., Sipiczki, M. \& Kohli, J. (1995). The rec8 gene of Schizosaccharomyces pombe is involved in linear element formation, chromosome pairing and sisterchromatid cohesion during meiosis. Genetics. Vol.141, No.1, pp.61-73, ISSN:00166731

Musio, A., Selicorni, A., Focarelli, M.L., Gervasini, C., Milani, D., Russo, S., Vezzoni, P. \& Larizza, L. (2006). X-linked Cornelia de Lange syndrome owing to SMC1L1 mutations. Nat Genet. Vol.38, No.5, pp.528-530, ISSN:1061-4036

Nabeshima, K., Villeneuve, A.M. \& Colaiacovo, M.P. (2005). Crossing over is coupled to late meiotic prophase bivalent differentiation through asymmetric disassembly of the SC. J Cell Biol. Vol.168, No.5, pp.683-689, ISSN:0021-9525

Nagao, K., Adachi, Y. \& Yanagida, M. (2004). Separase-mediated cleavage of cohesin at interphase is required for DNA repair. Nature. Vol.430, No.7003, pp.1044-1048, ISSN:1476-4687

Nasmyth, K. \& Haering, C.H. (2005). The structure and function of SMC and kleisin complexes. Annu Rev Biochem. Vol.74, pp.595-648

Neale, M.J. \& Keeney, S. (2006). Clarifying the mechanics of DNA strand exchange in meiotic recombination. Nature. Vol.442, No.7099, pp.153-158

Newman, J.J. \& Young, R.A. (2010). Connecting transcriptional control to chromosome structure and human disease. Cold Spring Harb Symp Quant Biol. Vol.75, pp.227-235, ISSN:1943-4456

Nishiyama, T., Ladurner, R., Schmitz, J., Kreidl, E., Schleiffer, A., Bhaskara, V., Bando, M., Shirahige, K., Hyman, A.A., Mechtler, K. \& Peters, J.M. (2010). Sororin mediates sister chromatid cohesion by antagonizing Wapl. Cell. Vol.143, No.5, pp.737-749, ISSN:1097-4172 
Notaridou, M., Quaye, L., Dafou, D., Jones, C., Song, H., Hogdall, E., Kjaer, S.K., Christensen, L., Hogdall, C., Blaakaer, J., McGuire, V., Wu, A.H., Van Den Berg, D.J., Pike, M.C., Gentry-Maharaj, A., Wozniak, E., Sher, T., Jacobs, I.J., Tyrer, J., Schildkraut, J.M., Moorman, P.G., Iversen, E.S., Jakubowska, A., Medrek, K., Lubinski, J., Ness, R.B., Moysich, K.B., Lurie, G., Wilkens, L.R., Carney, M.E., Wang-Gohrke, S., Doherty, J.A., Rossing, M.A., Beckmann, M.W., Thiel, F.C., Ekici, A.B., Chen, X., Beesley, J., Gronwald, J., Fasching, P.A., Chang-Claude, J., Goodman, M.T., Chenevix-Trench, G., Berchuck, A., Pearce, C.L., Whittemore, A.S., Menon, U., Pharoah, P.D., Gayther, S.A. \& Ramus, S.J. (2011). Common alleles in candidate susceptibility genes associated with risk and development of epithelial ovarian cancer. Int J Cancer. Vol.128, No.9, pp.2063-2074, ISSN:1097-0215

Novak, I., Wang, H., Revenkova, E., Jessberger, R., Scherthan, H. \& Hoog, C. (2008). Cohesin Smc1beta determines meiotic chromatin axis loop organization. J Cell Biol. Vol.180, No.1, pp.83-90, ISSN:1540-8140

Ong, C.T. \& Corces, V.G. (2011). Enhancer function: new insights into the regulation of tissue-specific gene expression. Nat Rev Genet. Vol.12, No.4, pp.283-293, ISSN:14710064

Page, J., Suja, J.A., Santos, J.L. \& Rufas, J.S. (1998). Squash procedure for protein immunolocalization in meiotic cells. Chromosome Res. Vol.6, No.8, pp.639-642,

Page, S.L. \& Hawley, R.S. (2004). The genetics and molecular biology of the synaptonemal complex. Annu Rev Cell Dev Biol. Vol.20, pp.525-558

Page, J., de la Fuente, R., Gomez, R., Calvente, A., Viera, A., Parra, M.T., Santos, J.L., Berrios, S., Fernandez-Donoso, R., Suja, J.A. \& Rufas, J.S. (2006). Sex chromosomes, synapsis, and cohesins: a complex affair. Chromosoma. Vol.115, No.3, pp.250-259, ISSN:0009-5915

Panizza, S., Tanaka, T., Hochwagen, A., Eisenhaber, F. \& Nasmyth, K. (2000). Pds5 cooperates with cohesin in maintaining sister chromatid cohesion. Curr Biol. Vol.10, No.24, pp.1557-1564, ISSN:0960-9822

Parra, M.T., Viera, A., Gomez, R., Page, J., Benavente, R., Santos, J.L., Rufas, J.S. \& Suja, J.A. (2004). Involvement of the cohesin Rad21 and SCP3 in monopolar attachment of sister kinetochores during mouse meiosis I. J Cell Sci. Vol.117, No.Pt 7, pp.1221-1234

Pasierbek, P., Jantsch, M., Melcher, M., Schleiffer, A., Schweizer, D. \& Loidl, J. (2001). A Caenorhabditis elegans cohesion protein with functions in meiotic chromosome pairing and disjunction. Genes Dev. Vol.15, No.11, pp.1349-1360, ISSN:0890-9369

Pelttari, J., Hoja, M.R., Yuan, L., Liu, J.G., Brundell, E., Moens, P., Santucci-Darmanin, S., Jessberger, R., Barbero, J.L., Heyting, C. \& Hoog, C. (2001). A meiotic chromosomal core consisting of cohesin complex proteins recruits DNA recombination proteins and promotes synapsis in the absence of an axial element in mammalian meiotic cells. Mol Cell Biol. Vol.21, No.16, pp.5667-5677

Peters, A.H., Plug, A.W., van Vugt, M.J. \& de Boer, P. (1997). A drying-down technique for the spreading of mammalian meiocytes from the male and female germline. Chromosome Res. Vol.5, No.1, pp.66-68

Pezzi, N., Prieto, I., Kremer, L., Perez Jurado, L.A., Valero, C., Del Mazo, J., Martinez, A.C. \& Barbero, J.L. (2000). STAG3, a novel gene encoding a protein involved in meiotic chromosome pairing and location of STAG3-related genes flanking the WilliamsBeuren syndrome deletion. Faseb J. Vol.14, No.3, pp.581-592 
Plug, A.W., Peters, A.H., Keegan, K.S., Hoekstra, M.F., de Boer, P. \& Ashley, T. (1998). Changes in protein composition of meiotic nodules during mammalian meiosis. $J$ Cell Sci. Vol.111 ( Pt 4), pp.413-423, ISSN:0021-9533

Polakova, S., Cipak, L. \& Gregan, J. (2011). RAD21L is a novel kleisin subunit of the cohesin complex. Cell Cycle. Vol.10, No.12, pp.1893, ISSN:1551-4005

Prieto, I., Suja, J.A., Pezzi, N., Kremer, L., Martinez, A.C., Rufas, J.S. \& Barbero, J.L. (2001). Mammalian STAG3 is a cohesin specific to sister chromatid arms in meiosis I. Nat Cell Biol. Vol.3, No.8, pp.761-766

Prieto, I., Pezzi, N., Buesa, J.M., Kremer, L., Barthelemy, I., Carreiro, C., Roncal, F., Martinez, A., Gomez, L., Fernandez, R., Martinez, A.C. \& Barbero, J.L. (2002). STAG2 and Rad21 mammalian mitotic cohesins are implicated in meiosis. EMBO Rep. Vol.3, No.6, pp.543-550, ISSN:1469-221X

Qiao, H., Lohmiller, L.D. \& Anderson, L.K. (2011). Cohesin proteins load sequentially during prophase I in tomato primary microsporocytes. Chromosome Res. Vol.19, No.2, pp.193-207, ISSN:1573-6849

Rankin, S. (2005). Sororin, the cell cycle and sister chromatid cohesion. Cell Cycle. Vol.4, No.8, pp.1039-1042, ISSN:1551-4005

Redon, C., Pilch, D., Rogakou, E., Sedelnikova, O., Newrock, K. \& Bonner, W. (2002). Histone H2A variants H2AX and H2AZ. Curr Opin Genet Dev. Vol.12, No.2, pp.162169, ISSN:0959-437X

Revenkova, E., Eijpe, M., Heyting, C., Gross, B. \& Jessberger, R. (2001). Novel meiosisspecific isoform of mammalian SMC1. Mol Cell Biol. Vol.21, No.20, pp.6984-6998

Revenkova, E., Eijpe, M., Heyting, C., Hodges, C.A., Hunt, P.A., Liebe, B., Scherthan, H. \& Jessberger, R. (2004). Cohesin SMC1 beta is required for meiotic chromosome dynamics, sister chromatid cohesion and DNA recombination. Nat Cell Biol. Vol.6, No.6, pp.555-562, ISSN:1465-7392

Revenkova, E. \& Jessberger, R. (2005). Keeping sister chromatids together: cohesins in meiosis. Reproduction. Vol.130, No.6, pp.783-790

Revenkova, E. \& Jessberger, R. (2006). Shaping meiotic prophase chromosomes: cohesins and synaptonemal complex proteins. Chromosoma. Vol.115, No.3, pp.235-240, ISSN:0009-5915

Royo, H., Polikiewicz, G., Mahadevaiah, S.K., Prosser, H., Mitchell, M., Bradley, A., de Rooij, D.G., Burgoyne, P.S. \& Turner, J.M. (2010). Evidence that meiotic sex chromosome inactivation is essential for male fertility. Curr Biol. Vol.20, No.23, pp.2117-2123, ISSN:1879-0445

Schalk, J.A., Dietrich, A.J., Vink, A.C., Offenberg, H.H., van Aalderen, M. \& Heyting, C. (1998). Localization of SCP2 and SCP3 protein molecules within synaptonemal complexes of the rat. Chromosoma. Vol.107, No.8, pp.540-548

Schmitz, J., Watrin, E., Lenart, P., Mechtler, K. \& Peters, J.M. (2007). Sororin is required for stable binding of cohesin to chromatin and for sister chromatid cohesion in interphase. Curr Biol. Vol.17, No.7, pp.630-636, ISSN:0960-9822

Shinohara, A. \& Shinohara, M. (2004). Roles of RecA homologues Rad51 and Dmc1 during meiotic recombination. Cytogenet Genome Res. Vol.107, No.3-4, pp.201-207

Skibbens, R.V., Corson, L.B., Koshland, D. \& Hieter, P. (1999). Ctf7p is essential for sister chromatid cohesion and links mitotic chromosome structure to the DNA replication machinery. Genes Dev. Vol.13, No.3, pp.307-319 
Skibbens, R.V. (2009). Establishment of sister chromatid cohesion. Curr Biol. Vol.19, No.24, pp.R1126-1132, ISSN:1879-0445

Sonoda, E., Matsusaka, T., Morrison, C., Vagnarelli, P., Hoshi, O., Ushiki, T., Nojima, K., Fukagawa, T., Waizenegger, I.C., Peters, J.M., Earnshaw, W.C. \& Takeda, S. (2001). Scc1/Rad21/Mcd1 is required for sister chromatid cohesion and kinetochore function in vertebrate cells. Dev Cell. Vol.1, No.6, pp.759-770

Stack, S.M. \& Anderson, L.K. (2009). Electron microscopic immunogold localization of recombination-related proteins in spreads of synaptonemal complexes from tomato microsporocytes. Methods Mol Biol. Vol.558, pp.147-169, ISSN:1064-3745

Strom, L., Lindroos, H.B., Shirahige, K. \& Sjogren, C. (2004). Postreplicative recruitment of cohesin to double-strand breaks is required for DNA repair. Mol Cell. Vol.16, No.6, pp.1003-1015

Strom, L. \& Sjogren, C. (2005). DNA damage-induced cohesion. Cell Cycle. Vol.4, No.4, pp.536-539, ISSN:1551-4005

Strom, L. \& Sjogren, C. (2007). Chromosome segregation and double-strand break repair - a complex connection. Curr Opin Cell Biol. Vol.19, No.3, pp.344-349, ISSN:0955-0674

Suja, J.A. \& Barbero, J.L. (2009). Cohesin complexes and sister chromatid cohesion in mammalian meiosis. Genome Dyn. Vol.5, pp.94-116

Sumara, I., Vorlaufer, E., Gieffers, C., Peters, B.H. \& Peters, J.M. (2000). Characterization of vertebrate cohesin complexes and their regulation in prophase. J Cell Biol. Vol.151, No.4, pp.749-762,

Szostak, J.W., Orr-Weaver, T.L., Rothstein, R.J. \& Stahl, F.W. (1983). The double-strandbreak repair model for recombination. Cell. Vol.33, No.1, pp.25-35, ISSN:0092-8674

Tanaka, T., Fuchs, J., Loidl, J. \& Nasmyth, K. (2000). Cohesin ensures bipolar attachment of microtubules to sister centromeres and resists their precocious separation. Nat Cell Biol. Vol.2, No.8, pp.492-499

Tarsounas, M., Morita, T., Pearlman, R.E. \& Moens, P.B. (1999). RAD51 and DMC1 form mixed complexes associated with mouse meiotic chromosome cores and synaptonemal complexes. J Cell Biol. Vol.147, No.2, pp.207-220, ISSN:0021-9525

Tonkin, E.T., Wang, T.J., Lisgo, S., Bamshad, M.J. \& Strachan, T. (2004). NIPBL, encoding a homolog of fungal Scc2-type sister chromatid cohesion proteins and fly Nipped-B, is mutated in Cornelia de Lange syndrome. Nat Genet. Vol.36, No.6, pp.636-641, ISSN:1061-4036

Toth, A., Ciosk, R., Uhlmann, F., Galova, M., Schleiffer, A. \& Nasmyth, K. (1999). Yeast cohesin complex requires a conserved protein, Eco1p(Ctf7), to establish cohesion between sister chromatids during DNA replication. Genes Dev. Vol.13, No.3, pp.320-333, ISSN:0890-9369

Uhlmann, F., Lottspeich, F. \& Nasmyth, K. (1999). Sister-chromatid separation at anaphase onset is promoted by cleavage of the cohesin subunit Scc1. Nature. Vol.400, No.6739, pp.37-42, ISSN:0028-0836

Uhlmann, F., Wernic, D., Poupart, M.A., Koonin, E.V. \& Nasmyth, K. (2000). Cleavage of cohesin by the CD clan protease separin triggers anaphase in yeast. Cell. Vol.103, No.3, pp.375-386, ISSN:0092-8674

Uhlmann, F. (2001). Chromosome cohesion and segregation in mitosis and meiosis. Curr Opin Cell Biol. Vol.13, No.6, pp.754-761 
Uhlmann, F. (2011). Cohesin subunit Rad21L, the new kid on the block has new ideas. EMBO Rep. Vol.12, No.3, pp.183-184, ISSN:1469-3178

Unal, E., Heidinger-Pauli, J.M., Kim, W., Guacci, V., Onn, I., Gygi, S.P. \& Koshland, D.E. (2008). A molecular determinant for the establishment of sister chromatid cohesion. Science. Vol.321, No.5888, pp.566-569, ISSN:1095-9203

Valdeolmillos, A.M., Viera, A., Page, J., Prieto, I., Santos, J.L., Parra, M.T., Heck, M.M., Martinez, A.C., Barbero, J.L., Suja, J.A. \& Rufas, J.S. (2007). Sequential loading of cohesin subunits during the first meiotic prophase of grasshoppers. PLoS Genet. Vol.3, No.2, pp.e28

Van Den Berg, D.J. \& Francke, U. (1993). Roberts syndrome: a review of 100 cases and a new rating system for severity. Am J Med Genet. Vol.47, No.7, pp.1104-1123, ISSN:01487299

Vega, H., Waisfisz, Q., Gordillo, M., Sakai, N., Yanagihara, I., Yamada, M., van Gosliga, D., Kayserili, H., Xu, C., Ozono, K., Jabs, E.W., Inui, K. \& Joenje, H. (2005). Roberts syndrome is caused by mutations in ESCO2, a human homolog of yeast ECO1 that is essential for the establishment of sister chromatid cohesion. Nat Genet. Vol.37, No.5, pp.468-470, ISSN:1061-4036

Verni, F., Gandhi, R., Goldberg, M.L. \& Gatti, M. (2000). Genetic and molecular analysis of wings apart-like (wapl), a gene controlling heterochromatin organization in Drosophila melanogaster. Genetics. Vol.154, No.4, pp.1693-1710, ISSN:0016-6731

Viera, A., Rufas, J.S., Martinez, I., Barbero, J.L., Ortega, S. \& Suja, J.A. (2009a). CDK2 is required for proper homologous pairing, recombination and sex-body formation during male mouse meiosis. J Cell Sci. Vol.122, No.Pt 12, pp.2149-2159, ISSN:00219533

Viera, A., Santos, J.L. \& Rufas, J.S. (2009b). Relationship between incomplete synapsis and chiasma localization. Chromosoma. Vol.118, No.3, pp.377-389

Waizenegger, I.C., Hauf, S., Meinke, A. \& Peters, J.M. (2000). Two distinct pathways remove mammalian cohesin from chromosome arms in prophase and from centromeres in anaphase. Cell. Vol.103, No.3, pp.399-410, ISSN:0092-8674

Wallace, B.M.N. \& Jones, G.H. (1978). Incomplete chromosome pairing and its relation to chiasma localisation in Stethophyma grossum spermatocytes. Heredity. Vol.40, pp.385-396

Wang, T.F., Kleckner, N. \& Hunter, N. (1999). Functional specificity of MutL homologs in yeast: evidence for three Mlh1-based heterocomplexes with distinct roles during meiosis in recombination and mismatch correction. Proc Natl Acad Sci U S A. Vol.96, No.24, pp.13914-13919

Watanabe, Y. \& Nurse, P. (1999). Cohesin Rec8 is required for reductional chromosome segregation at meiosis. Nature. Vol.400, No.6743, pp.461-464,

Watanabe, Y. (2004). Modifying sister chromatid cohesion for meiosis. J Cell Sci. Vol.117, No.Pt 18, pp.4017-4023

Watrin, E. \& Peters, J.M. (2006). Cohesin and DNA damage repair. Exp Cell Res. Vol.312, No.14, pp.2687-2693, ISSN:0014-4827

Xu, H., Beasley, M., Verschoor, S., Inselman, A., Handel, M.A. \& McKay, M.J. (2004). A new role for the mitotic RAD21/SCC1 cohesin in meiotic chromosome cohesion and segregation in the mouse. EMBO Rep. Vol.5, No.4, pp.378-384 
Xu, H., Beasley, M.D., Warren, W.D., van der Horst, G.T. \& McKay, M.J. (2005). Absence of mouse REC8 cohesin promotes synapsis of sister chromatids in meiosis. Dev Cell. Vol.8, No.6, pp.949-961, ISSN:1534-5807

Yuan, L., Liu, J.G., Zhao, J., Brundell, E., Daneholt, B. \& Hoog, C. (2000). The murine SCP3 gene is required for synaptonemal complex assembly, chromosome synapsis, and male fertility. Mol Cell. Vol.5, No.1, pp.73-83

Zetka, M.C., Kawasaki, I., Strome, S. \& Muller, F. (1999). Synapsis and chiasma formation in Caenorhabditis elegans require HIM-3, a meiotic chromosome core component that functions in chromosome segregation. Genes Dev. Vol.13, No.17, pp.2258-2270, ISSN:0890-9369

Zhang, L., Tao, J., Wang, S., Chong, K. \& Wang, T. (2006). The rice OsRad21-4, an orthologue of yeast Rec8 protein, is required for efficient meiosis. Plant Mol Biol. Vol.60, No.4, pp.533-554, ISSN:0167-4412

Zhang, B., Jain, S., Song, H., Fu, M., Heuckeroth, R.O., Erlich, J.M., Jay, P.Y. \& Milbrandt, J. (2007). Mice lacking sister chromatid cohesion protein PDS5B exhibit developmental abnormalities reminiscent of Cornelia de Lange syndrome. Development. Vol.134, No.17, pp.3191-3201, ISSN:0950-1991

Zhang, N., Kuznetsov, S.G., Sharan, S.K., Li, K., Rao, P.H. \& Pati, D. (2008a). A handcuff model for the cohesin complex. J Cell Biol. Vol.183, No.6, pp.1019-1031, ISSN:15408140

Zhang, J., Shi, X., Li, Y., Kim, B.J., Jia, J., Huang, Z., Yang, T., Fu, X., Jung, S.Y., Wang, Y., Zhang, P., Kim, S.T., Pan, X. \& Qin, J. (2008b). Acetylation of Smc3 by Eco1 is required for $S$ phase sister chromatid cohesion in both human and yeast. Mol Cell. Vol.31, No.1, pp.143-151, ISSN:1097-4164

Zhang, J., Hakansson, H., Kuroda, M. \& Yuan, L. (2008c). Wapl localization on the synaptonemal complex, a meiosis-specific proteinaceous structure that binds homologous chromosomes, in the female mouse. Reprod Domest Anim. Vol.43, No.1, pp.124-126, ISSN:0936-6768 


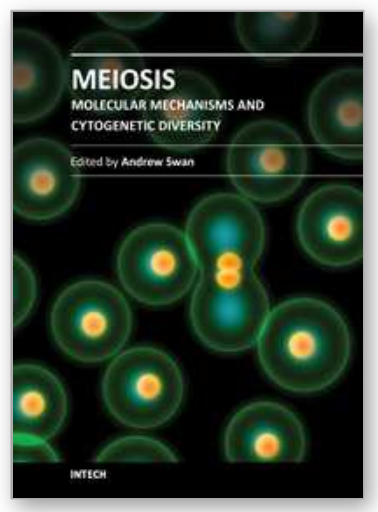

\author{
Meiosis - Molecular Mechanisms and Cytogenetic Diversity \\ Edited by Dr. Andrew Swan
}

ISBN 978-953-51-0118-5

Hard cover, 472 pages

Publisher InTech

Published online 29, February, 2012

Published in print edition February, 2012

Meiosis, the process of forming gametes in preparation for sexual reproduction, has long been a focus of intense study. Meiosis has been studied at the cytological, genetic, molecular and cellular levels. Studies in model systems have revealed common underlying mechanisms while in parallel, studies in diverse organisms have revealed the incredible variation in meiotic mechanisms. This book brings together many of the diverse strands of investigation into this fascinating and challenging field of biology.

\title{
How to reference
}

In order to correctly reference this scholarly work, feel free to copy and paste the following:

Adela Calvente and José L. Barbero (2012). Cohesins and Cohesin-Regulators in Meiosis, Meiosis - Molecular Mechanisms and Cytogenetic Diversity, Dr. Andrew Swan (Ed.), ISBN: 978-953-51-0118-5, InTech, Available from: http://www.intechopen.com/books/meiosis-molecular-mechanisms-and-cytogenetic-diversity/cohesinsand-cohesin-regulators-in-mammalian-meiosis

\section{INTECH}

open science | open minds

\section{InTech Europe}

University Campus STeP Ri

Slavka Krautzeka 83/A

51000 Rijeka, Croatia

Phone: +385 (51) 770447

Fax: +385 (51) 686166

www.intechopen.com

\section{InTech China}

Unit 405, Office Block, Hotel Equatorial Shanghai

No.65, Yan An Road (West), Shanghai, 200040, China

中国上海市延安西路65号上海国际贵都大饭店办公楼 405 单元

Phone: +86-21-62489820

Fax: +86-21-62489821 
(C) 2012 The Author(s). Licensee IntechOpen. This is an open access article distributed under the terms of the Creative Commons Attribution 3.0 License, which permits unrestricted use, distribution, and reproduction in any medium, provided the original work is properly cited. 